\title{
The Influence of Unknown Media on Public Opinion: Evidence from Local and Foreign News Sources
}

\author{
Erik Peterson and Maxwell B. Allamong* \\ Texas A\&M University \\ Department of Political Science
}

\section{Forthcoming at the American Political Science Review}

\begin{abstract}
In the Internet era people can encounter a vast array of political news outlets, many of which they are unfamiliar with. These unknown media outlets are notable because they represent potential sources of misinformation and coverage with a distinctive slant. We use two large survey experiments to consider how source familiarity influences political communication. While this demonstrates the public is averse to consuming news from unfamiliar media, we show thatconditional on exposure to them-unknown local and foreign media sources can influence public opinion to an extent similar to established mainstream news outlets on the same issues. This comparable effectiveness stems from the public's charitable evaluations of the credibility of unfamiliar news sources and their relatively low trust in familiar mainstream media. We find avoidance of unknown news outlets, not resistance to their coverage, is the key factor limiting their political influence.
\end{abstract}

\footnotetext{
${ }^{*}$ Corresponding author email: erik.peterson@tamu.edu. Erik Peterson is an Assistant Professor of Political Science at Texas A\&M University. Maxwell Allamong is a Ph.D. Candidate in Political Science at Texas A\&M University. The authors thank Johanna Dunaway and Sean Westwood for helpful comments and suggestions.
} 
The 20th century media landscape centered on print and television media and was characterized by high costs of entry for news producers and a limited set of choices for news consumers (Mutz and Martin 2001, Hamilton 2004, Prior 2007). In the Internet era, these barriers to entry and constraints on choice have fallen away, resulting in a massive expansion in the number of accessible news sources (Munger 2020, Pennycook and Rand 2019, Van Aelst et al. 2017, Hindman 2008, Metzger et al. 2003). The public can now see political coverage from a vast array of media-local, national, even foreign news outlets - many of which they are unfamiliar with.

Unknown media outlets are notable, in part, because they represent potential sources of misinformation and slanted coverage not previously available in many settings (Lazer et al. 2018, Guess et al. 2020). Here we focus on newly available, and largely unknown, local and foreign media outlets that have introduced distinctive political news coverage into local and national politics. In local politics, the decline of newspapers (Hayes and Lawless 2015, 2018; Darr et al. 2018; Peterson 2021) coincides with the emergence of networks of hyper-partisan local news websites. These outlets push a partisan agenda and often have no presence in the communities they purport to cover (Mahone and Napoli 2020). In national politics, online news use means foreign propaganda can easily reach American audiences. This prompted the U.S. Department of Justice to require RT, an English-language news source sponsored by the Russian government, to register as a foreign agent in 2017 (Stubbs and Gibson 2017).

Although the emergence of unfamiliar news sources is relevant to many political settings, the implications of the public's encounters with them remain unclear. Previous studies primarily consider sources with established reputations. They find that trustworthy news outlets can more effectively influence opinion than media viewed as untrustworthy (Hovland et al. 1953, Petty and Cacioppo 1986, Miller and Krosnick 2000, Druckman 2001, Chong and Druckman 2007, Ladd 2010), that the public resists messages from media they associate with their political opponents (Zaller 1992, Levendusky 2013, Hopkins and Ladd 2014), and that media brands influence news use (Stroud 2008, Iyengar and Hahn 2009). 
Given the importance of media reputations, how does the public respond to unknown news sources that lack defined profiles? We consider how source familiarity impacts two aspects of the political communication process. The first are decisions about whether or not to consume news from an outlet. The second are responses to its political coverage. At both stages we hypothesize unfamiliar sources will be disadvantaged relative to familiar media, with people more likely to avoid their coverage and more resistant to messages it contains.

We examine the use of, and response to, news from unfamiliar and familiar media sources in two large survey experiments $(n=6,042$ and $n=5,068)$ on diverse national samples. ${ }^{1}$ The experiments consider several issues where unfamiliar sources are relevant: state tax policy, perceptions of polarization in American politics, views on the integrity of the 2020 U.S. presidential election and the perceived threat of cyber attacks to the government and economy of the United States. On each topic we elicited news preferences before randomly assigning respondents to see a story from a familiar source, view the same article attributed to an unfamiliar outlet, or not see any news (i.e., a "patient preference" design, see Arceneaux and Johnson 2013, Levendusky 2013 and De Benedictis-Kessner et al. 2019). This lets us measure the public's willingness to seek news from unfamiliar media, estimate the effect of encountering unfamiliar news sources on public opinion, and compare it to a familiar media outlet's influence on the same issue.

The experiments reveal source familiarity plays a large role in news choice, with people far less willing to select coverage from unfamiliar media than from sources they are familiar with. Conditional on exposure, however, the experiment shows unfamiliar local and foreign media sources can influence public opinion. Contrary to our expectations, the effects of exposure to these unknown sources are similar to those of mainstream media with much greater familiarity when pooling the five studies into a summary estimate. Moreover, the influence of unfamiliar news sources is not confined to those who seek them out. Even among

1 The samples were provided by Lucid and quota sampled to match census benchmarks for age, gender, ethnicity and region. 
people who prefer to avoid unfamiliar media, encountering their coverage affects opinion.

Our results make important contributions to understanding political communication in the contemporary high-choice media environment. Previous work emphasizes media outlet reputations matter due to how they condition responses to news coverage showing, for instance, the public's resistance to messages from media they perceive as untrustworthy (Zaller 1992, Miller and Krosnick 1998, Druckman 2001). Given exposure to their coverage, we instead find unfamiliar news sources to be as effective at shifting public opinion as familiar media with established reputations. We attribute this to two developments. First, the public evaluates these unfamiliar news sources in a neutral, rather than negative, manner. Second, sustained declines in media trust over the past several decades have reduced the premium for familiar media relative to unknown sources. Rather than resistance to news from unknown sources, we find avoidance of unfamiliar news outlets is the primary factor limiting their contemporary political influence.

\section{Source Reputations and Media Effects}

Holding a speaker's message constant, an expansive literature finds that communicators regarded as credible and likable are more persuasive than those lacking these characteristics (Hovland and Weiss 1951, Aronson et al. 1963, Chaiken 1980, Mondak 1993, Lupia and McCubbins 1998, Pornpitakpan 2004). Such broad arguments about the importance of source reputations receive further support in studies of political media. Miller and Krosnick (2000) and Ladd (2010) find those low in media trust are less responsive to messages contained in political coverage. Druckman (2001) shows issue frames from an untrustworthy news source (the National Enquirer) are ineffective, while the same frames delivered by a trustworthy source (the New York Times) can change public opinion (see also Chong and Druckman 2007, Petty and Cacioppo 1986). Relatedly, source reputations matter insofar as the public resists messages conveyed by media they perceive as incongruent with their political predispositions (Zaller 1992, Levendusky 2013, Hopkins and Ladd 2014).

Other research considers how reputations affect news exposure. Partisan cable channels 
attract those sharing their party label and repel out-party members (Stroud 2011, Levendusky 2013, Martin and Yurukoglu 2017). Similarly, online outlets with distinctive reputations have a partisan divide in their audiences (Iyengar and Hahn 2009, De BenedictisKessner et al. 2019, Tyler et al. ND). Affinity for co-partisan media appears to operate via perceived trustworthiness, as people continue to rely on co-partisan outlets in news selection experiments when monetary incentives are introduced for correctly answering political knowledge questions (Peterson and Iyengar 2021, Luca et al. ND).

Common to research on communication effects and news use is a focus on media with established reputations. These studies require the public have a sense of the media's overall trustworthiness (Ladd 2012, Archer 2020, Goidel et al. 2021) or the reputations of individual sources (Baum and Gussin 2007, Peterson and Kagalwala 2021), leading to the study of wellknown outlets such as MSNBC, Fox News, CNN or USA Today (Coe et al. 2008, Levendusky and Malhotra 2016, Mummolo 2016, Martin and Yurukoglu 2017, Clayton et al. 2019).

\section{Unfamiliarity as an Element of Media Reputations}

While established media are key information sources, the ease of entry into the digital media landscape has greatly expanded the number of relevant political news options (Munger 2020, Pennycook and Rand 2019, Hindman 2008, Metzger et al. 2003). The array of media the public can now encounter far exceeds the number of sources they are aware of. This makes unfamiliarity, like trustworthiness, a facet of media reputation that merits attention.

A 2019 study by the Pew Research Center illustrates this point (Jurkowitz et al. 2020). Pew surveyed a nationally representative sample about their awareness of 30 news sources representing popular political media from across the ideological spectrum. The average respondent was unfamiliar with $31 \%$ of these sources. Even among these prominent political news outlets, many brand reputations were not broad, as only 11 sources were known by $80 \%$ or more of respondents (see also Pennycook and Rand 2019).

This limited awareness of media reputations coexists with a news environment in which people can potentially encounter a vast number of media outlets. While it is difficult to pre- 
cisely characterize the number of sources relevant for contemporary news use, recent studies show the breadth of options. Dilliplane et al. (2013) measure exposure to 49 different political television programs. Flaxman et al. (2016) report the Open Directory Project lists nearly 8,000 web domains providing news coverage. Based on lists of prominent news websites, Peterson et al. (2021) consider web traffic to 355 political news domains and Gentzkow and Shapiro (2011) do so for 1,379 news outlets. Bakshy et al. (2015) examine content sharing patterns for 500 news websites on Facebook. While news use remains concentrated among prominent outlets (Hindman 2018, 2008; Guess ND; Tyler et al. ND), this shows media sources with plausible political relevance now number in the hundreds, if not thousands, far beyond the set of news outlets with clear public reputations.

\section{Source Familiarity and News Choice}

Our study concerns how political communication-both exposure to news and responses to media coverage when it is encountered-proceeds when incorporating unfamiliarity as an element of media source reputations. We first consider how unfamiliarity impacts news choice. Although some may avoid familiar media they distrust (Tsfati and Cappella 2003) or be inattentive to media reputations, previous work suggests the lack of an established brand is an impediment for unfamiliar news sources competing against more familiar alternatives.

Based on the "recognition heuristic," in which people make positive inferences about an object's traits based on recognizing it (Goldstein and Gigerenzer 2002, Kam and Zechmeister 2013), Metzger et al. (2010) argue mere familiarity with a news organization's logo and name will enhance its credibility relative to unknown media outlets (see also Sundar 2008). This suggests negative assessments of their credibility will make unknown media outlets less appealing information sources. Furthermore, unlike unfamiliar outlets, established media sources have had the opportunity to secure a routine place in people's news diets, serving as a habitual default when they make news use decisions (Mutz and Young 2011, Stroud 2008).

Ideological considerations can also advantage media with distinct partisan brands. In today's highly segmented media landscape, news outlets cater to political views across the 
ideological spectrum (Mullainathan and Shleifer 2005). Based on this, we expect some of the familiar sources available when people select media coverage will have cultivated positive reputations, offering an advantage relative to outlets without a profile due to the anticipated congeniality of their news coverage.

Empirically, Iyengar and Hahn (2009) demonstrate the value of familiar news source reputations. First, they find people continue to rely on popular political media brands even for coverage of non-political topics (see also Stroud 2011). Second, when news stories are presented without a source, interest in them is lower. The problem anonymous news reports face in attracting interest suggests similar issues for unknown media outlets.

\section{Expectations: Source Familiarity and News Choice}

Based on prior literature, we expect familiar outlets will be advantaged, relative to unfamiliar outlets, at the news selection stage. This leads to our first hypothesis ${ }^{2}$

H1: Familiarity with a news source will increase interest in consuming its coverage.

\section{Responding to News from Unfamiliar Media}

Beyond news exposure, we also consider how source familiarity conditions responses to political news coverage. What happens when the public encounters news from unknown media sources? Two perspectives emerge from previous research on source credibility that examines the issue in a variety of contexts.

Here the recognition heuristic suggests unfamiliar sources will be evaluated as untrustworthy and, accordingly, be ineffective at influencing public opinion. Pennycook and Rand (2019) crowd-source assessments of online news sources and find unfamiliar hyper-partisan outlets are perceived as less credible than mainstream media, aligning with how Metzger et al. (2010) found people discussed unfamiliar news sources in their focus groups. Indicative of the ineffectiveness of unknown sources, Weisbuch et al. (2003) show a speaker an audience

2 Our hypotheses and analysis were pre-registered at: https://aspredicted.org/ 7cr4m.pdf and https://aspredicted.org/uk24n.pdf. 
has encountered before is more influential than an unknown speaker. Coan et al. (2008) observe limited cue effects from minor parties (i.e., the Green party) among those unfamiliar with them (see also Brader et al. 2012). Dragojlovich (2013) finds cues from unknown foreign politicians are ineffective, while recognizable foreign leaders can move public opinion (see also Hayes and Guardino 2011).

Others claim unfamiliar sources are evaluated in a neutral manner, potentially enabling them to persuade the public. Weber et al. (2012) find campaign ads from an unknown interest group are more effective than attributing them to an established, but polarizing, interest group (see also Brooks and Murov 2012, Jungherr et al. 2021). Broockman et al. (2021) show people respond favorably to interest group candidate endorsements, even with no idea of the group's positions. This happens because they assume the stances of unfamiliar groups align with their own.

Closest to our focus, several studies ask people to assess the trustworthiness of unfamiliar or fictional news outlets. While coverage from these sources is typically evaluated as less credible than coverage from real sources (but see Dias et al. 2020), news from fictional outlets with innocuous names (e.g., "DailyNewsReview.com") is still typically rated as relatively trustworthy (Bauer and Clemm von Hohenberg ND, Sterrett et al. 2019, Greer 2003).

A final point is that even studies emphasizing source credibility's importance observe instances in which untrustworthy sources move opinion. In one such case, Hovland et al. (1953, 36) note "presumably the arguments contained in the communications produced large enough positive effects to counteract negative effects due to the communicator." Dual process models distinguishing heuristic (based on source cues) and systematic (based on message content) processing conclude source cues have a substantial influence on public opinion in most ordinary circumstances, but that an unreliable messenger may not fully undermine an otherwise effective message (Chaiken 1980, Petty and Cacioppo 1986). 


\section{Expectations: Effects of Familiar and Unfamiliar Media}

We anticipate both familiar and unfamiliar news sources will influence opinion when a news article is attributed to them. For familiar sources, this follows from prior demonstrations that positive source reputations facilitate influence (Hovland et al. 1953, Druckman 2001). The expectation for unfamiliar media is less clear, but we see previous work as supporting the notion that unfamiliar news sources may influence opinion not because they have acquired a favorable reputation, but because they lack an overly negative one (Weber et al. 2012). This produces our second and third hypotheses.

H2: Exposure to a news article from a familiar media source will move opinion towards the views in its coverage.

H3: Exposure to a news article from an unfamiliar media source will move opinion towards the views in its coverage.

We also anticipate heterogeneity in these effects. The political communication literature's emphasis on the effectiveness of messages from sources perceived as credible and trustworthy suggests familiar sources will be more effective than unfamiliar sources. This leads to our fourth hypothesis.

H4: Exposure to a news article from a familiar media source will be more influential than exposure to the same article from an unfamiliar media source.

\section{Who Do Unfamiliar Media Outlets Influence?}

Finally, we consider heterogeneity in responses to coverage from unfamiliar news sources among those who would (or would not) seek them out. One theme of extant work on misinformation is that some characteristics (e.g., lack of cognitive reflection, high need for certainty) predict both a willingness to seek out unreliable information sources and a ten- 
dency to credulously accept claims these outlets make (Mosleh et al. 2021, Guess et al. 2020, Federico and Malka 2018). Relatedly, some studies of partisan media find people resist messages from cross-cutting sources they would prefer to avoid if forced to encounter such coverage (Levendusky 2013). This bundled perspective suggests the acceptance of messages from unfamiliar media should be concentrated among those interested in their coverage, while resistance should be stronger among those avoiding unfamiliar news sources.

However, it is also possible news preferences and information processing operate in a more decoupled manner. The decision to avoid an unfamiliar source may not mean people would resist the source's coverage if they encountered it. Recent political psychology work supports this perspective by arguing that partisan differences in misinformation are not due to innate between-group differences in willingness to accept inaccurate claims or follow partisan cues, but derive instead from differential patterns of information exposure (Guay and Johnston ND, Ryan and Aziz 2021). In other words, on issues where they exhibit less misinformation, Democrats may not be able to more effectively resist misinformed claims than Republicans, they may just more successfully avoid such content. Similarly, some studies of partisan media find cross-cutting exposure to out-party news sources can influence opinion (Conroy-Krutz and Moehler 2015, Martin and Yurukoglu 2017, Clayton et al. 2019, De Benedictis-Kessner et al. 2019, Levy 2021), suggesting an aversion to consuming a source's coverage does not preclude being influenced by it.

\section{Expectations: Conditional Effects of Unfamiliar Media}

Either because they are inattentive to source cues, or have a desire to avoid established media, our fifth hypothesis is that those interested in seeking out unfamiliar news sources will respond to their coverage.

H5: Exposure to a news article from an unfamiliar media source will move opinion, among those who select it. 
We have mixed expectations about the effects of unfamiliar media among those who prefer to avoid them. One possibility is that unfamiliar sources will not influence this group, with their coverage evaluated similarly to news from outlets with negative reputations. Alternatively, unfamiliar sources could move opinion even among those who prefer to avoid them. This may occur if unfamiliar sources are perceived in a neutral manner, leading to less resistance among the group avoiding them. We lay out competing expectations about the effects of unfamiliar media among this group in our sixth hypothesis.

H6a: Exposure to a news article from an unfamiliar media source will not move opinion, among those who prefer to avoid it.

H6b: Exposure to a news article from an unfamiliar media source will move opinion, among those who prefer to avoid it.

\section{Unfamiliar Local and Foreign News Sources}

Before turning to experiments testing these hypotheses, we discuss the unfamiliar news sources studied here. While many unfamiliar news sources merit consideration, we focus on hyper-partisan local news websites and RT, an English-language media outlet financed by the Russian government. This is because these sources are both unfamiliar and provide distinctive political coverage in important policy domains.

First, the decline of newspapers has opened opportunities for new, online local political coverage (Hayes and Lawless 2015, 2018; Darr et al. 2018; Peterson 2021). This shift has enabled hyper-partisan news outlets to enter the local media market. Mahone and Napoli (2020) document networks of hundreds of local news websites that, despite names conveying a geographic affiliation, typically have a limited local presence and provide ideologically slanted political coverage. In one notable instance, a false story criticizing Hillary Clinton published by the "Denver Guardian," a website created months before and with no ties to the city, was widely shared on social media during the 2016 election (Lubbers 2016). Such unfamiliar local outlets may be able to leverage the public's positive views of local media to 
push a partisan agenda (Martin and McCrain 2019 study this in local TV news).

Second, we consider foreign news exposure, a possibility given how Internet access has relaxed geographic constraints on news use. We focus on RT (formerly Russia Today), an English-language media outlet sponsored by the Russian government, because it allows Americans exposure to foreign propaganda through RT's website, cable television channel and the re-circulation of its content on social media. RT's coverage emphasizes themes of conflict and decline in American domestic politics and American over-extension in foreign affairs (Elswah and Howard 2020). In important studies, Fisher (2020) and Carter and Carter (2021) show exposure to RT can change American's foreign policy views, but do not compare this to the influence of domestic media or measure perceptions of RT's reputation, topics we take up here while focusing on its coverage of American domestic politics.

One commonality of unfamiliar local and foreign news sources is their production of coverage that, in its appearance, resembles reporting produced by more familiar, mainstream news sources. For instance, Elswah and Howard (2020) document RT's reliance on professional journalists, along with political employees, to ensure the outlet's messages are packaged in a way that appears familiar to news consumers. We see this appropriation of news styles from familiar sources as one reason to anticipate unfamiliar news outlets may be able to effectively influence public opinion. Accordingly, we incorporate this type of coverage from unfamiliar sources into our experiments and leave the public's response to clearly unprofessional coverage from unfamiliar sources for future work.

\section{Experimental Design}

We consider the use and effects of unfamiliar and familiar media sources in two surveys containing five experiments. Table 1 describes the experimental design. The first survey had 6,042 respondents and was conducted in late January-early February 2021. It included Studies 1, 2 and 3. The second survey had 5,068 respondents and was conducted in late June-early July 2021. This survey contained Studies 4 and 5. In both cases, the samples were recruited by Lucid and drawn to match nationally representative quotas for age, gender 
and ethnicity (see Coppock and McClellan 2019 on this subject pool).$^{3}$

Before discussing each study's topic, we outline the experimental design shared across them. In each study respondents were first presented with a menu of news options and indicated which they would prefer to read coverage from. This design lets us examine interest in different news sources and estimate the conditional effects of news from unfamiliar sources among those who would or would not choose to encounter them.

For Studies 1, 2 and 3 news selection occurred immediately before respondents saw a news article. In contrast, Studies 4 and 5 included a washout period on unrelated topics between when respondents made news selections and when they saw news articles. This change in the second survey minimizes any demand characteristics that might change how respondents evaluate the coverage they encounter, particularly from the unfamiliar sources we expect many will not have selected in the news choice tasks (but see Mummolo and Peterson 2019 on the limited evidence for demand effects in online survey experiments.)

Table 1: Summary of Experimental Designs

\begin{tabular}{l|l|l|l|l}
\hline & Dependent Variable & News Article & Familiar Source & Unfamiliar Source \\
\hline Study 1 & Tax Opinion & State Tax Policy Criticism & Newspaper from State & Partisan Local Website \\
Study 2 & Perceived Polarization & Highlighting Partisan Divide & USA Today & RT \\
Study 3 & Belief in Voter Fraud & Correcting Election Misinfo & Newspaper from State & Fictional State Newspaper \\
Study 4 & Tax Opinion & State Tax Policy Criticism & Newspaper from State & Partisan Local Website \\
Study 5 & Cyber Security & Cyber Attack Threat & USA Today & RT \\
\hline
\end{tabular}

In the news exposure portion of the experiment, respondents encountered one of three randomly assigned conditions. The control group answered questions without news exposure. Those in the familiar source treatment read an article attributed to a large newspaper from their state (Study 1, Study 3 and Study 4) or USA Today (Study 2 and Study 5). These sources were selected due to their widespread familiarity, perceived trustworthiness and to avoid media evoking sharply polarized evaluations between Democrats and Republicans. Finally, respondents in the unfamiliar source treatment read the same article, instead attributed to a partisan news website in their state (Study 1 and Study 4), RT (Study 2 and

\footnotetext{
3 See Appendix A for survey demographics.
} 
Study 5), or a fictional news website from their state (Study 3). In Study 3 these fictional newspaper names were produced by combining the state's name with a common newspaper title (i.e., "Times", "Tribune", or "News") and selected to avoid overlapping with the names of prominent news sources available in the state.4

We emphasized an article's source in two ways. Respondents were initially informed of the source of the article on a separate page before encountering it. After clicking through to read the story, the outlet's logo was prominently displayed as they read. Using a post-treatment attention check, we later confirm respondents took note of the article's source.

The studies focused on a variety of issues where unfamiliar news sources are relevant. For Studies 1 and 4, the article criticized the tax system in a respondent's state and noted its poor performance in a national ranking. This was based on an article from a partisan local website. We anticipate this will negatively affect opinions about state taxes.

Study 2's article discussed partisan divisions among the mass public and politicians, emphasizing that Congressional gridlock poses an impediment to progress on major problems facing the United States. Such coverage frequently appears in Russian messaging on RT and social media (Kim et al. 2018, Elswah and Howard 2020, Bail et al 2020, Carter and Carter 2021). We expect the article to increase perceptions of a polarized, gridlocked government and elevate pessimism about the country's future. Others demonstrate coverage from established media sources can have this effect (Levendusky and Malhotra 2016), we consider whether an unfamiliar media source can accomplish this.

Study 3 used an Associated Press story debunking false claims of widespread fraud in the 2020 Presidential election, wire copy likely to appear in local newspapers. Consistent with past work on correcting allegations of voter fraud (Holman and Lay 2019, but see Berlinski et al. ND), we expect the article to increase confidence in the election's integrity.

Finally, based on RT's coverage in the weeks preceding our second survey, Study 5's article focused on the negative consequences of cyber attacks for the economy and government of the

\footnotetext{
${ }^{4}$ Appendix Table B1 contains a list of these sources.
} 
United States. We expect this to elevate public perceptions of the threat of cyber attacks.

These topics vary in ways aimed to improve the generalizability of the set of experiments. Studies 1, 2, 4 and 5 use content originally produced by unfamiliar media sources to see if it is more influential when attributed to a familiar source. Study 3 reverses this, examining whether local newspaper coverage is less influential when attributed to an unknown source, potentially making it easier to discount.

In terms of the direction in which public opinion was expected to move, the anti-tax messaging in Studies 1 and 4 aligns with the rhetoric of Republican elites, while the fact check in Study 3 pushes against false claims of widespread voter fraud endorsed by Republican politicians. Studies 2 and 5 have a less clear partisan valence, focusing on complaints about polarization in American politics and the threat of cyber attacks to the United States.

Finally, these issues offer a view of the relative effectiveness of media source reputations across topics that are likely to be more (i.e., state tax policy) or less (i.e., perceived polarization) amenable to influence from any type of media source based on the degree to which the public possesses well formed opinions when entering the study.

\section{Source Familiarity Predicts News Choice}

We begin by examining how self-reported familiarity with a news source predicts a willingness to seek information from it. We measure source familiarity at the start of the survey, where respondents saw a checklist with the names and logos of various media outlets and indicated which they had previously heard of. We relate this familiarity measure to their news selections in the survey. Prior to the experimental treatments, respondents saw a menu of options and were asked which media outlet they would prefer to read. In Studies 1, 3 and 4 the choice set consisted of four local media sources determined based on a respondent's state of residence (Appendix Table B1 shows each state's source list). These were a large newspaper from the respondent's state, a local partisan website, a non-profit media outlet covering the respondent's state and a fictional newspaper from their state. In Studies 2 and 5 the choice set contained five media sources. Four were chosen to represent established infor- 
mation sources at a variety of positions on the ideological spectrum: Fox News, Huffington Post, USA Today, and the New York Times. The fifth option was RT.

To relate source familiarity to news choice, we create separate observations for each option in a choice task. This results in 124,158 news source selections made across the two surveys. We regress an indicator variable for whether the respondent selected that news option on an indicator variable for whether they were familiar with the source. In the left column of Table 2, we assess this bivariate relationship with no controls. In the right column we include person and source fixed effects in the regression, isolating within-subject variation in familiarity with news sources and netting out fixed personal-level characteristics, such as political interest, and source characteristics, such as an outlet more appealing to everyone whether or not they previously heard of it. We display robust standard errors, clustered by respondent, to account for dependencies in each news selection (i.e., in each task choosing one option meant not selecting the others).

Table 2: Probability of Selecting News Source by Familiarity

\begin{tabular}{lcc}
\hline & Bivariate & Person and Source FEs \\
\hline Familiar with Source & $0.26^{*}$ & $0.27^{*}$ \\
& $(0.002)$ & $(0.004)$ \\
\hline Observations & 124,158 & 124,158 \\
\hline Note: & ${ }^{*} \mathrm{p}<0.05$ & \\
& Robust Standard Errors, Clustered by Respondent
\end{tabular}

Table 2 shows familiarity is a strong predictor of news choice across both specifications, providing support for Hypothesis 1, the expectation unfamiliar sources would be disadvantaged compared to familiar media at the news selection stage. Relative to news sources they are unfamiliar with, respondents are 26 percentage points more likely to choose a news source they reported familiarity with. While familiarity is hardly a guarantee of selection, respondents chose news sources they were not familiar with only $9 \%$ of the time, while choosing sources they reported familiarity with $35 \%$ of the time $5^{5}$

\footnotetext{
${ }^{5}$ Familiar source selection is not higher as respondents were often familiar with multiple
} 
We illustrate the substantive relevance of this difference based on familiarity by comparing it to partisanship, another strong predictor of news choice. In Studies 2 and 5, which featured national media, Republicans were 39 percentage points more likely than Democrats to select Fox News. In contrast, Democrats were 29 percentage points more likely than Republicans to select the New York Times. So, while slightly smaller, the difference in news selection predicted by source familiarity rivals the size of the partisan divide for two outlets with strong ideological reputations.

\section{Effects of Familiar and Unfamiliar Sources}

Having established source familiarity's importance at the news selection stage, we consider its relevance for responses to news coverage. In our pre-registration plans, we specified how each analysis would be conducted. For each outcome we use an index constructed by performing principal components analysis on multiple survey items addressing the article's topic $\sqrt[6]{ }$ We standardize these outcomes to have mean zero and standard deviation one and orient them so that exposure to the article is expected to move respondents in a positive direction. So, for Study 1 and Study 4 higher scale values indicate more anti-tax attitudes, in Study 2 higher values indicate a more polarized and pessimistic view of American politics, for Study 3 higher values indicate more confidence in the integrity of the 2020 election and in Study 5 higher values indicate more concern about the consequences of cyber attacks for the United States.

For each study, we regress the outcome on indicator variables for the familiar and unfamiliar news treatments to estimate the effect of each relative to the control group. The regressions include additional covariates specified in our pre-analysis plans, such as a respondent's partisanship and pre-treatment measures related to the outcomes of each study to reduce uncertainty in the effect estimates (Clifford et al. ND, see Appendix A). Finally, we committed to pooling the five studies into a summary estimate using a fixed effect meta

sources in each task, meaning selecting one familiar source meant not choosing others.

${ }^{6}$ Individual survey items are outlined in Appendix A. 
analysis, weighting the effects of each study by how precisely they are estimated.

These decisions were made to increase the precision of the treatment effect estimates. We do so because, beyond how articles from unfamiliar and familiar news sources influence opinion, a key question is whether the effect of familiar sources differs from unfamiliar sources. This requires precise estimates of each individual treatment effect to test appropriately, as we expect the difference between the familiar and unfamiliar treatment effects to be less stark then between either treatment and control.

Before proceeding, we note the familiar and unfamiliar treatments substantially differ in how aware respondents were of the outlets in them. Summarizing the five studies, only $21 \%$ of respondents had heard of outlets in the unfamiliar treatments. In contrast, $78 \%$ of respondents were aware of the sources in the familiar treatments of the experiments.7

\section{Experimental Results}

We now examine the effects of familiar and unfamiliar news sources. Figure 1 displays these estimates and the associated $95 \%$ confidence intervals $8^{8}$ We first discuss the figure's left panel, which displays the treatment effect estimates of the familiar source (black points) and the unfamiliar source (gray points) on each topic along with the estimate pooling the five studies. These reflect the number of standard deviations exposure to the news article moved respondents on the outcome scale compared to those in the control condition.

\footnotetext{
${ }^{7}$ See Appendix A2 each news source's familiarity.

8 Tabular results are available in Appendix C.
} 
Figure 1: News Article Effects By Source
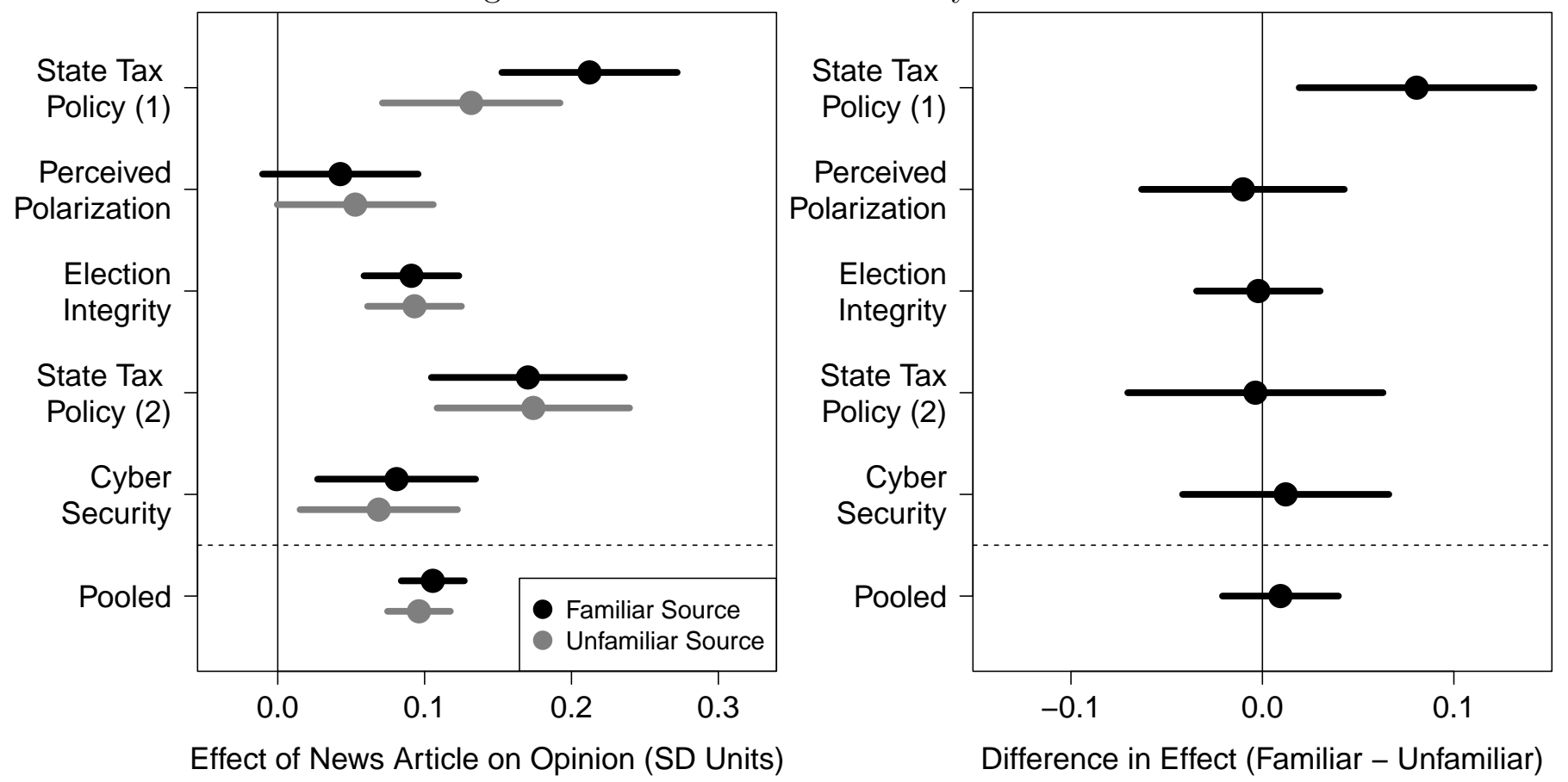

Consistent with our second and third hypotheses, exposure to both the familiar and unfamiliar sources influenced public opinion on these topics. In Study 1 both the familiar $(0.21$, $95 \%$ CI $[0.15,0.27])$ and unfamiliar source $(0.13,95 \%$ CI $[0.07,0.19])$ exerted a statistically significant effect, with encounters with an anti-tax message from either media source leading people to hold more negative views of their state's tax policy.

The estimated effects of the two sources are of roughly similar magnitude and in the expected direction in Study 2, with those in the treatment conditions perceiving higher levels of gridlock and political polarization than those in control. However, both estimates fall short of the threshold for statistical significance we use throughout the paper $(\mathrm{p}=0.05$ for RT, $\mathrm{p}=0.12$ for USA Today), as exposure to the unfamiliar source (RT) produced an increase of 0.05 standard deviations (95\% CI $[-0.01,0.11])$ in perceived polarization, while encountering the same article from USA Today produced a 0.04 effect $(95 \%$ CI $[-0.01,0.10])$.

In Study 3 encountering the article debunking false claims of voter fraud increased confidence in the integrity of the 2020 Presidential election. Despite the salient nature of this 
issue when we conducted the study, these effects occurred whether the article was attributed to the familiar source of a large newspaper from the respondent's state $(0.09,95 \%$ CI $[0.06$, $0.12])$ or the unfamiliar fictional newspaper source $(0.09,95 \%$ CI $[0.06,0.13])$.

For Study 4, which used the same anti-tax article as Study 1, the unfamiliar $(0.18,95 \%$ CI $[0.11,0.24])$ and familiar outlets $(0.17,95 \%$ CI $[0.11,0.24])$ both influenced opinion, this time exhibiting a similar ability to generate negative views of state taxes.

Study 5, which examined public concern over the threat posed by cyber attacks to the United States, again revealed influence from both the familiar $(0.08,95 \%$ CI $[0.03,0.14])$ and unfamiliar $(0.07,95 \%$ CI $[0.02,0.12])$ news outlets, with those encountering coverage expressing greater concern about cyber attacks.

In Studies 4 and 5, on the second survey, greater separation between the news selection tasks and when respondents encountered coverage did not reduce the influence of unfamiliar sources compared to more familiar alternatives. This suggests the proximity of these items in the initial survey does not contribute to the effect of unknown news sources on opinion, removing a potential explanation in which these findings are an artifact of survey design.

Pooling the five studies together, we see an effect of 0.11 standard deviations (95\% CI $[0.08,0.13])$ for the familiar sources and $0.10(95 \%$ CI $[0.08,0.12])$ for the unfamiliar sources. Altogether this strongly supports Hypotheses 2 and 3. Political coverage from both unfamiliar and familiar news sources influenced opinion across the different topics in the experiments.

To give a sense of the magnitude of these effects, we compare them to the divide between Republicans and Democrats in the control group. On one end, the effect of the familiar source is sizeable in Studies 1 and 4, at roughly half the size of the baseline partisan divide over state taxation. In contrast in Studies 2 and 3, which consider polarized national topics, the effects of familiar sources are only $4 \%$ and $6 \%$ the size of the partisan divide in control. So, while not always large, these studies show coverage from both unfamiliar and familiar news sources can meaningfully change opinion on a set of political issues that vary in the degree to which public opinion is malleable in response to news coverage. 
While we cannot assess the persistence of these effects here, another important aspect of their political relevance, prior literature on the persistence of survey experimental treatment effects offers some guidance. We note that, while the news articles contain a mix of considerations that may shape public opinion, they all emphasize new information that respondents might otherwise not have (e.g., about the poor performance of their state on a tax ranking in Studies 1 and 4). This resembles the class of informational survey experimental effects for which scholars have hypothesized (Baden and Lecheler 2012) and found (Coppock et al. 2018) greater over-time durability than those operating through other mechanisms, such as elevating the accessibility of considerations individuals were already aware of.

\section{Heterogeneity by Source Type}

We next assess the relative influence of familiar and unfamiliar news sources in the right panel of Figure 1. Here our expectation was that familiar media sources would be more influential than the unfamiliar sources. We test this by assessing the difference between the treatment effects of each source category (i.e., the difference between the effect of familiar sources and the effect of unfamiliar sources). If familiar sources are more influential, these difference in difference estimates will be positive.

Study 1 provides support for this expectation on tax policy. Here the effect of the familiar source was $60 \%$ larger than the effect of the unfamiliar source $(0.08,95 \%$ CI $[0.02,0.14])$.

However, in the other studies, or when pooling together the results of the five experiments, we do not find support for this expectation. In the other experiments included on the first survey, Study $2(-0.01,95 \%$ CI $[-0.06,0.04])$ and Study $3(-0.01,95 \%$ CI $[-0.03,0.03])$, there is not a distinguishable difference between the familiar and unfamiliar news sources.

On the second survey in both Study $4(-.01,95 \%$ CI $[-0.07,0.06])$, which replicated the lone experiment (Study 1) with a detectable difference between the familiar and unfamiliar sources, and Study $5([0.01,95 \%$ CI $[-0.04,0.07])$ the difference in the effects of familiar and unfamiliar outlets is small and we are unable to reject the null hypothesis the two source types have the same effect. 
This similarity extends to the pooled estimate which indicates the effect of familiar sources is roughly $10 \%$ larger than unfamiliar sources, but is not statistically significant $(0.01,95 \%$ CI $[-0.02,0.04])$. Taken altogether, we fail to find support for Hypothesis 4 and instead observe that coverage from the two sets of sources had largely equivalent effects on public opinion, with Study 1 the lone exception. 9

While we are cautious about embracing the null hypothesis, given a failure to reject it, our study design allows us to rule out large differences in the influence of familiar and unfamiliar news sources. To show this we conduct an equivalence test-which instead sets a difference in the effects of familiar and unfamiliar news sources as the null hypothesis - to determine the range of values for which this null can be rejected in favor of the alternative hypothesis that unfamiliar and familiar news sources have meaningfully similar effects. Using the $90 \%$ confidence interval of the pooled difference in the effect of familiar and unfamiliar sources allows rejection of differences outside this interval at the 0.05 level, in favor of the alternative of no meaningful difference (Rainey 2014, Hartman and Hidalgo 2018).

Here the $90 \%$ confidence interval on the difference in the effects of familiar and unfamiliar sources runs from -0.02 to 0.04 . This means we can reject the null hypothesis of familiar sources being more influential than unfamiliar sources for any difference of more than 0.04, or roughly 35 percent more influential than the pooled effect of unfamiliar sources, in favor of the alternative hypothesis of no meaningful difference in the effects of the two source types. While this does not preclude familiar outlets exerting more influence than unfamiliar sources, a valuable contribution of this study is to rule out large differences between them.

We later discuss explanations for the similar effects of familiar and unfamiliar media outlets, but one possibility we address here is that respondents were simply inattentive to a story's source, which might explain their similar effects. In each study half the respondents reading an article were randomly assigned to an attention check. They were asked to recall

\footnotetext{
${ }^{9}$ We observe similar results using self-reported familiarity with a news source as a moderating variable. See Appendix C3.
} 
the source that produced the article from a menu with four to five options. Source recall was high, as $74 \%$ of respondents in the treatment conditions correctly recalled the source they encountered (see Appendix C for results by study). Given this, inattention to source labels does not appear to explain the similar effects of unfamiliar and familiar news sources.

\section{Summary: How Does Source Familiarity Matter?}

Before proceeding to the effects of unfamiliar news sources among different groups, we revisit our expectations in light of the evidence on the overall effects of familiar and unfamiliar news sources on public opinion. We hypothesized two channels through which source familiarity might impact political communication effects. First, in an indirect channel, it might alter an individual's propensity to consume news coverage from a source (Hypothesis 1). Second, in a direct channel, it might alter responses to the coverage a news source provides (Hypothesis 4) 10

Based on our evidence, unfamiliar and familiar news sources are distinguished almost entirely by this indirect channel. Table 2 shows people are much more likely to select coverage from a familiar source. An alternative way of describing this is to note that, summarizing the choice tasks in the five experiments, respondents selected the sources in the unfamiliar treatments only $14 \%$ of the time, while selecting sources from the familiar treatments $38 \%$ of the time.

However, our assessment of effect heterogeneity in the preceding section shows there is limited evidence for a direct channel, in which familiarity alters responses to the coverage a news source provides. Pooling the various studies, we see a null effect on the difference in the effects of familiar and unfamiliar sources $(0.01,95 \%$ CI $[-0.02,0.04])$. Across these studies the consequences of source familiarity for political communication appear to operate indirectly, through differences in exposure decisions, rather than directly through responses to news coverage given exposure to it.

\footnotetext{
${ }^{10}$ We thank a reviewer for suggesting this terminology.
} 


\section{Effects of Unfamiliar Sources by News Preference}

Moving beyond the average effects of each news source, we turn to the effects of unfamiliar sources among those who engage (or avoid) them when able to do so. We test our conditional hypotheses using the patient preference component of the study in which respondents revealed their preferences for consuming news from various media sources. During each study all respondents, whether they were in a condition that would expose them to news or not, were presented with a menu of news options and asked to select which source they would like to encounter information from. We use this question to separate respondents into two groups. The first are those who selected the unfamiliar news source. To test Hypothesis 5 , we examine the effects of unfamiliar sources among this group. The second group consists of those who did not select the source from the unfamiliar treatment when presented with the opportunity to do so. We estimate the effects of unfamiliar sources among this group to adjudicate between our competing expectations in Hypotheses 6a and 6b.

Table 3 displays these conditional treatment effect estimates. For each study it shows the effect of unfamiliar media sources among a group, along with the associated $95 \%$ confidence interval. The table also indicates the share of the sample in that category for each study. As in the previous section, we pool the five studies together using a fixed effects meta analysis.

Table 3: Effect of Article from Unfamiliar News Source by News Preference

\begin{tabular}{lcc|cc} 
& \multicolumn{2}{c}{ Chose Unfamiliar Source } & \multicolumn{2}{c}{ Avoided Unfamiliar Source } \\
\hline & Article Effect & Share in Category & Article Effect & Share in Category \\
\hline Study 1 & $0.17[0.06,0.28]$ & 0.30 & $0.12[0.04,0.19]$ & 0.70 \\
Study 2 & $-0.13[-0.47,0.21]$ & 0.03 & $0.06[0.01,0.11]$ & 0.97 \\
Study 3 & $0.10[0.03,0.17]$ & 0.22 & $0.09[0.05,0.13]$ & 0.78 \\
Study 4 & $0.18[-0.02,0.38]$ & 0.13 & $0.16[0.09,0.23]$ & 0.87 \\
Study 5 & $-0.02[-0.37,0.34]$ & 0.03 & $0.07[0.02,0.13]$ & 0.97 \\
\hline Pooled & $0.10[0.04,0.15]$ & 0.14 & $0.10[0.07,0.12]$ & 0.86 \\
\hline
\end{tabular}

We first consider the left columns of the table, which display the effect of encountering unfamiliar news sources among respondents who indicated a preference for these outlets in 
the patient preference portion of the study. In Studies 1, 3, 4, and when pooling the results, unfamiliar media influence opinion among this group as expected. The pooled estimate indicates that, among the $14 \%$ of the sample willing to select these sources, exposure to a news article from an unfamiliar media source moved opinion by 0.10 standard deviations $(95 \%$ CI $[0.04,0.15])$ relative to the control group. This supports Hypothesis 5 , the expectation unfamiliar outlets will influence opinion among those willing to seek them out.

The aberrant results in Study 2 and Study 5 merit some attention. In both, among the $3 \%$ of the sample selecting RT the effect of encountering its coverage is negative, though estimated with a wide confidence interval $(-0.13,95 \%$ CI $[-0.47,0.21]$ in Study 2 and -0.02, 95\% CI [0.37, 0.34] in Study 5). We view these as idiosyncratic results of the small portion of the sample willing to select this source, which makes the estimate highly imprecise as in Study 2, for instance, it involves only 180 respondents spread across three treatment arms.

Turning to Table 3's right columns, we consider the competing expectations about the effects of unfamiliar news sources among those who avoided such sources in the news selection task. Once again, unfamiliar news sources influenced opinion across all five studies. The effects of unfamiliar news sources on opinion, among people who avoid them in the news selection task, are statistically significant and range from 0.06 to 0.16 SDs. In the pooled results, the effect of encountering coverage from the unfamiliar source is a 0.10 standard deviation shift $(95 \%$ CI $[0.07,0.12])$ in opinion among the 86 percent of the sample that avoided the unfamiliar news source when selecting coverage.

The combined set of results provides strong support for Hypothesis 6b. An aversion to consuming information from the unfamiliar source did not lead people to resist its coverage if they encountered it. Altogether, the pooled effects of unfamiliar sources are of similar magnitude among both those who would avoid them or seek them out. This illustrates the relevance of news selection for understanding constraints on the influence of unfamiliar sources. When choosing news, most avoided the unfamiliar source. The conditional treatment effect shows these "avoiders" would be influenced by coverage from the unfamiliar 
source, if they were to see it 11

\section{Discussion}

Our experiments show unknown local and foreign media sources can influence public opinion about local and national politics. Rather than any resistance to their coverage, unfamiliar media outlets appear more hamstrung by their lack of popularity when competing for attention against established media brands. We conclude by discussing the implications of these findings.

\section{Charitable Views of Unfamiliar Media}

Conditional on exposure to their coverage, familiar and unfamiliar news outlets had a similar influence on public opinion. This was inconsistent with the pattern we expected. Why were these sources similarly effective? We see this as the combination of a tendency for respondents to evaluate unknown media in a neutral manner and the declines in trust of mainstream news sources that have occurred over the past several decades. We begin by comparing the reputations of the news sources in the familiar and unfamiliar treatment conditions in Table 4, using measures of their perceived trustworthiness and ideological bias collected at the start of the first survey 12

Table 4: Comparing Perceptions of Media in Familiar and Unfamiliar Treatments

\begin{tabular}{lrrrr}
\hline Treatment & Aware & Trust & Moderate & Perceived Distance \\
\hline Unfamiliar Source & 0.23 & 0.44 & 0.53 & 0.26 \\
Familiar Source & 0.78 & 0.51 & 0.45 & 0.26 \\
\hline
\end{tabular}

The familiar sources are rated, on average, at the middle of the trustworthiness scale ( 0.51 ; near the point labeled "Moderately trustworthy"), affording them an advantage of about $7 \%$ of the trust scale's width over sources in the unfamiliar treatments (0.44). In

\footnotetext{
${ }^{11}$ We report similar results in Appendix C4 using additional choice tasks in the second survey that also incorporated entertainment media into the news selection stage.

${ }^{12}$ These continuous measures are re-coded to lie between zero and one. See Appendix A.2 for results by news source.
} 
terms of perceived ideology, respondents placed unfamiliar news sources at the "neutral" mid-point of the scale (53\%) more frequently than the familiar outlets (45\%). Finally, there is no difference in the perceived ideological distance - the absolute difference of a respondent's self-placement on an ideology scale and their placement of the media source on the same scale-between the familiar and unfamiliar sources. Despite the large gulf in awareness of the two sets of outlets, in many other respects the public evaluated them similarly.

One element behind the similar effects of familiar and unfamiliar news outlets is the charitable assessments unfamiliar media sources received. People regarded unknown media as somewhat trustworthy and presumed they were moderate, rather than viewing them as untrustworthy and ideologically incongruent, a finding consistent with some other work considering unknown and fictional news sources (see Bauer and Clemm von Hohenberg ND, Sterrett et al. 2019, Greer 2003) 13

This differs from Pennycook and Rand (2019), who find unfamiliar fake and hyperpartisan outlets are largely mistrusted. One difference is the unfamiliar outlets in this study mimic the naming conventions of established media (e.g., the "Texas Business Daily"), which garners them more trust than the outlets Pennycook and Rand (2019) consider (e.g., "angrypatriotmovement.com").

Explaining the sources of trust in unfamiliar media is a needed topic for future work. We suspect the domain a news source covers has some role in this, as trust is high in all the local media options we consider, with the partisan and fictional local websites receiving similar levels of trust to high-quality local non-profit news sources (See Appendix Tables A4 and A5). Beyond this, other cues conveyed by the title and logos of unfamiliar sources are likely have a role in determining the public's evaluation of them (e.g., Metzger et al. 2010). In Appendix Table D2, we also find that those with higher overall levels of trust in the media

\footnotetext{
13 This tendency to evaluate unknown sources in a neutral manner also has methodological implications, potentially explaining the public's responses to news coverage and issue frames in experiments (e.g., Chong and Druckman 2007, Exp. 1) where no source cue is provided.
} 
are more likely to trust unfamiliar news sources.

More broadly, these findings have mixed implications for research on the recognition heuristic, which motivated our theoretical expectations. Respondents trusted familiar news sources more than unfamiliar outlets (see Appendix Table D1) and were more likely to seek coverage from them, patterns consistent with the recognition heuristic. However, conditional on exposure, familiar and unfamiliar sources had similar effects on opinion. Here the difference in trust did not appear large enough to produce different responses to the coverage familiar and unfamiliar news sources provided.

\section{Declining Trust in Mainstream Media}

In addition to the neutral evaluations unfamiliar news outlets received, a second contributing factor is declines in trust of established news sources. In a manifestation of this trend, Figure 2 shows data from Pew Research Center surveys regarding the share of the public rating USA Today's coverage as "believable." This fell from $72 \%$ in 1986 to $48 \%$ in 2012, the most recent year with comparable question wording.

Figure 2: Believability of USA Today by Year

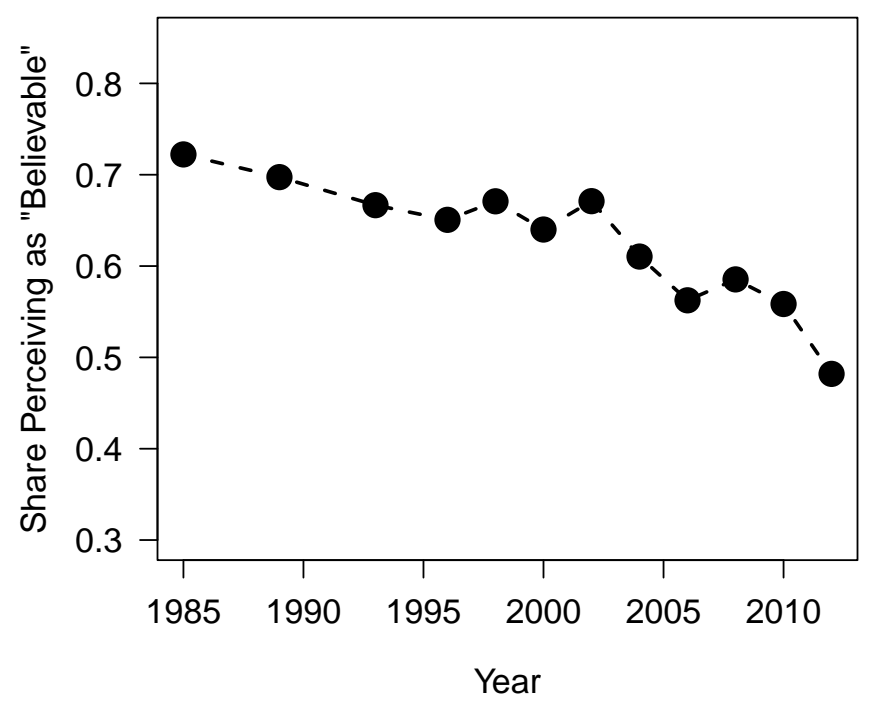

Figure displays the share of respondents, among those providing a rating, that "Believe all or most" of USA Today's coverage in Pew Research Center surveys from 1985 to 2012. 
This large decline in trust in one of the "familiar" news outlets we study is representative of the broader decline in trust of established media over the past several decades (Ladd 2012, Archer 2020). Few sources today have the familiar and widely trusted reputations of the media outlets in prior studies showing the potency of source cues from familiar mainstream news sources. The familiar media in our experiments resemble this as closely as any in contemporary politics as USA Today and local newspapers are both highly familiar and at least moderately trusted by both Republicans and Democrats.

Overall, our survey shows familiar, mainstream news sources remain more trusted than others, but this advantage is small. While we cannot assess how people evaluated unfamiliar news sources in the past, we suspect the premium in trust between familiar mainstream news sources and unknown media has declined compared to earlier eras, contributing to their similar effectiveness in these experiments.

\section{Source Familiarity in a High-Choice Media Environment}

We considered two ways familiar news sources might be advantaged relative to unknown media. We found limited evidence their coverage is inherently more influential than it would be if attributed to other news sources. On the other hand, even if messages from familiar sources are not inherently more effective than those from unfamiliar outlets, we found strong support that source familiarity advantages them at the news exposure stage. This suggests the chief advantage familiar sources possess in contemporary politics is their ability to garner large audiences in a fragmented news environment, something emphasized in studies of online exposure to national news outlets (Hindman 2008, Guess ND, Tyler et al. ND) and, in a relative sense, for online exposure to local media (Hindman 2018).

\section{How Might Encounters With Unfamiliar Media Occur?}

Given the main impediment we identify to the influence of unknown media sources is the public's lack of interest in consuming news from them, a question for future research becomes understanding how encounters with unfamiliar media might happen. This is all the more important as, based on the patient preference aspect of our study, even those who 
would ordinarily avoid such outlets still respond to their coverage if exposed to it.

Considering the news choice portion of the experiments, we find those with low levels of overall media trust were more likely than others to select the unfamiliar news sources, although the magnitude of this relationship is small (i.e., a one standard deviation decrease in media trust was predicted to increase unfamiliar source selection by 1 percentage point; See Appendix D), suggesting a dislike of known and familiar options makes unfamiliar news sources more attractive (see also Tsafi and Capella 2003), but also demonstrating the need for further consideration of the factors beyond low overall media trust that lead people to trust and engage with unfamiliar news sources. We also note that many respondents incorrectly stated they were familiar with fictional news sources throughout the study (e.g., 35\% said they had heard of Study 3's fictional newspaper), suggesting "mistaken familiarity" might promote the use of unfamiliar sources in some cases.

Beyond low media trust, other literatures suggest ways in which encounters with unfamiliar news sources could happen. Offsetting cues, such as social media recommendations, may help an unknown media source overcome its disadvantage at the news exposure stage (Messing and Westwood 2014, Grinberg et al. 2019, Sterrett et al. 2019). Social media also creates opportunities for incidental news exposure not driven by active considerations (Kim et al. 2018, Feezell 2018, Bakshy et al. 2015). Other countervailing factors, like coverage of topics particularly interesting to some, might overcome the disadvantages of an unknown source label (Mummolo 2016). While more investigation is needed, this suggests several avenues through which unfamiliar news outlets can reach broader audiences.

\section{Conclusion}

Decades of research on persuasion emphasize the importance of source cues in making messages from familiar, trusted sources influential. Reconsidering this in contemporary politics, we find unfamiliar media sources without a pre-existing reputation can effectively influence opinion, to a degree similar to the influence of familiar mainstream media sources. Instead, the power of familiar media sources in the fragmented contemporary media envi- 
ronment is more in their ability to capture a large audience, than in any inherent difference in the effectiveness of their messages. This similarity in effectiveness between these different sources appears to stem from declining trust in familiar mainstream news outlets, coupled with a tendency for people to provide neutral evaluations of unfamiliar news sources.

Our findings do not mean unfamiliar news sources have an unconstrained ability to shape public opinion as news sources of all types, unfamiliar or not, face limitations in their ability to move public opinion on salient issues where the public has already established well formed opinions. However, this study reveals that on a variety of relevant local and national political issues and with news sources that range from local newspapers to a Russian-sponsored media outlet, it cannot be taken for granted that messages from unfamiliar media will be ineffective merely because they originate from an unknown source. 


\section{References}

Archer, Allison. 2020. "Attacking the Fourth Estate: The Nature and Effects of Political Leaders' War with the Press." In Leadership, Populism and Resistance (Eds. Krisitin M.S. Bezio and Al Goethals). Pages 129-147. Edward Elgar.

Arceneaux, Kevin and Martin Johnson. 2013. Changing Minds or Changing Channels? Partisan News in an Age of Choice University of Chicago Press.

Aronson, Elliot, Judith A. Turner and J. Merrill Carlsmith. 1963. "Communicator Credibility and Communication Discrepancy as Determinants of Opinion Change." Journal of Abnormal and Social Psychology 67(1): 31-36.

Baden, Christian and Sophie Lecheler. 2012. "Fleeting, Fading, or Far-Reaching? A Knowledge-Based Model of the Persistence of Framing Effects." Communication Theory 22(4): $359-382$.

Bail, Christopher A., Brian Guay, Emily Maloney, Aidan Combs, D. Sunshine Hillygus, Friedolin Merhout, Deen Freelon and Alexander Wolfovsky. 2020. "Assessing the Russian Internet Research Agency's Impact on the Political Attitudes and Behaviors of American Twitter users in late 2017." Proceedings of the National Academy of Science 117(1): 243250.

Bakshy, Eytan, Solomon Messing and Lada A. Adamic. 2015. "Exposure to Ideologically Diverse News and Opinion on Facebook." Science 348(6239): 1130-1132.

Bauer, Paul C. and Bernhard Clemm von Hohenberg. ND. "Believing and Sharing Information by Fake Sources." Political Communication Forthcoming.

Baum, Matthew and Phil Gussin. 2007. "In the Eye of the Beholder: How Information Shortcuts Shape Individual Perceptions of Bias in the Media." Quarterly Journal of Political Science 3(1): 1-31.

Berlinski, Nicolas, Margaret Doyle, Andrew M. Guess, Gabrielle Levy, Benjamin Lyons, Jacob M. Montgomery, Brendan Nyhan and Jason Reifler. ND. "The Effect of Unsubstantiated Claims of Voter Fraud on Confidence in Elections." Journal of Experimental 
Political Science Forthcoming.

Brader, Ted, Joshua A. Tucker and Dominik Duell. 2012. "Which Parties Can Lead Opinion? Experimental Evidence on Partisan Cue Taking in Multiparty Democracies." Comparative Political Studies 46(11): 1485-1517.

Broockman, David E., Aaron R. Kaufman and Gabriel S. Lenz. 2021. "Heuristic Projection: How Interest Group Cues Can Harm Voters' Judgements." Working Paper. https://osf. io/6yskq

Brooks, Deborah Jordan and Michael Murov. 2012. "Assessing Accountability in a PostCitizens United Era: The Effects of Attack Ad Sponsorship by Unknown Independent Groups." American Politics Research 40(3): 383-418.

Carter, Erin Baggott and Bret L. Carter. 2021. "Questioning More: RT, Outward Facing Propaganda, and the Post-West World Order." Security Studies 30(1): 49-78.

Chaiken, Shelly. 1980. "Heuristic versus Systematic Information Processing and the Use of Source Versus Message Cues in Persuasion." Journal of Personality and Social Psychology 39(5): 752-766.

Chong, Dennis and James N. Druckman. 2007. "Framing Public Opinion in Competitive Democracies." American Political Science Review 101(4): 637-655.

Clayton, Katherine, Jase Davis, Kristen Hinckley and Yusaku Horiuchi. 2019. "Partisan Motivated Reasoning and Misinformation in the Media: Is News from Ideologically Uncongenial Sources More Suspicious." Japanese Journal of Political Science 20(3): 129-142.

Clifford, Scott, Geoffrey Sheagley and Spencer Piston. ND. "Increasing Precision without Altering Treatment Effects: Repeated Measures Designs in Survey Experiments." American Political Science Review Forthcoming.

Coan, Travis G., Jennifer Merolla, Laura Stephenson and Elizabeth Zechmeister. 2008. "It's Not Easy Being Green: Minor Party Labels as Heuristic Aids." Political Psychology 29(3): 389-405.

Coe, Kevin, David Tewskbury, Bradley J. Bond, Kristin L. Drogos, Robert W. Porter, Ashley 
Yahn and Yuanyuan Zhang. 2008. "Hostile News: Partisan Use and Perceptions of Cable News Programming."' Journal of Communication 58(2): 201-219.

Conroy-Krutz, Jeffrey and Devra C. Moehler. 2015. "Moderation from Bias: A Field Experiment on Partisan Media in a New Democracy." Journal of Politics 77(2), 575-587. Coppock, Alexander and Oliver A. McClellan. 2019. "Validating the Demographic, Political, Psychological, and Experimental Results Obtained From a New Source of Online Survey Respondents." Research $E$ P Politics 6(1): 1-14.

Coppock, Alexander, Emily Elkins and David Kirby. 2018. "The Long-Lasting Effects of Newspaper Op-Eds on Public Opinion." Quarterly Journal of Political Science 13(1): $59-87$.

Darr, Joshua, Matthew Hitt and Johanna Dunaway. 2018. "Newspaper Closures Polarize Voting Behavior." Journal of Communication 68(6): 1007-1028.

De Benedictis-Kessner, Justin, Matthew Baum, Adam J. Berinsky and Teppei Yamamoto. 2019. "Persuading the Enemy: Estimating the Persuasive Effects of Partisan Media with the Preference-Incorporating Choice and Assignment Design." American Political Science Review 113(4): 902-916.

Dias, Nicholas, Gordon Pennycook and David G. Rand. 2020. "Emphasizing Publishers Does Not Effectively Reduce Susceptibility to Misinformation on Social Media." Harvard Kennedy School Misinformation Review 1(1).

Dilliplane, Susanna, Seth K. Goldman and Diana C. Mutz. 2013. "Televised Exposure to Politics: New Meausres for a Fragmented Media Environment" American Journal of Political Science 57(1): 236-248.

Dragojlovic, Nick. 2013. "Leaders Without Borders: Familiarity as a Moderator of Transnational Source Cue Effects." Political Communication 30(2): 297-316.

Druckman, James N. 2001. "On the Limits of Framing Effects: Who Can Frame?" Journal of Politics 63(4): 1041-1066.

Elswah, Mona and Philip N. Howard. 2020. " 'Anything that Causes Chaos': The Organi- 
zational Behavior of Russia Today (RT)." Journal of Communication 70 (5): 623-645.

Feezell, Jessica T. 2018. "Agenda Setting Through Social Media: The Importance of Incidental News Exposure and Social Filtering in the Digital Era." Political Research Quarterly $71(2): 482-494$.

Federico, Christopher M. and Ariel Malka. 2018. "The Contingent, Contextual Nature of the Relationship Between Needs for Security and Certainty and Political Preferences." Advances in Political Psychology 39(1): 3-48.

Fisher, Alexsandr. 2020. "Demonizing the Enemy: The Influence of Russian State-Sponsored Media on American Audiences." Post-Soviet Affairs 36(4): 281-296.

Flaxman, Seth, Sharad Goel and Justin M. Rao. 2016. "Filter Bubbles, Echo Chambers, and Online News Consumption." Public Opinion Quarterly 80(S1): 298-320.

Gentzkow, Matthew and Jesse M. Shapiro. 2011. "Ideological Segregation Online and Offline." Quarterly Journal of Economics 126(4): 1799-1839.

Goidel, Kirby, Nicholas T. Davis and Spencer Goidel. 2021. "Changes in Perceptions of Media Bias." Research \& Politics 8(1): 1-9.

Goldstein, Daniel G. and Gerd Gigerenzer. 2002. "Models of Ecological Rationality." Psychological Review 109(1): 75-90.

Greer, Jennifer D. 2003. "Evaluating the Credibility of Online Information." Mass Communication and Society 6(1): 11-28.

Grinberg, Nir, Kenneth Joseph, Lisa Freidland, Briony Swire-Thompson and David Lazer. 2019. "Fake News on Twitter During the 2016 U.S. Presidential Election." Science 363: 374-378.

Guay, Brian and Christopher Johnston. ND. "Ideological Asymmetries and the Determinants of Politically Motivated Reasoning." American Journal of Political Science. Forthcoming.

Guess, Andrew M. ND. “(Almost) Everything in Moderation: New Evidence on Americans' Online Media Diets." American Journal of Political Science Forthcoming.

Guess, Andrew M., Brendan Nyhan and Jason Reifler. 2020. "Exposure to Untrustworthy 
Websites in the 2016 US Election." Nature Human Behavior 4: 472-480.

Hamilton, James T. 2004. All the News That's Fit To Sell. Princeton University Press.

Hartman, Erin and F. Daniel Hidalgo. 2018. "An Equivalence Approach to Balance and

Placebo Tests." American Journal of Political Science 62(4): 1000-1013.

Hayes, Danny and Matt Guardino. 2011. "The Influence of Foreign Voices on US Public Opinion." American Journal of Political Science 55(4): 831-851.

Hayes, Danny and Jennifer L. Lawless. 2015. "As Local News Goes, So Goes Citizen Engagement: Media, Knowledge, and Participation in US House Elections." Journal of Politics 77(2), 447-462.

Hayes, Danny and Jennifer L. Lawless. 2018. "The Decline of Local News and Its Effects: New Evidence from Longitudinal Data." Journal of Politics 80(1): 332-336.

Hindman, Matthew. 2018. The Internet Trap. Princeton University Press.

Hindman, Matthew. 2008. The Myth of Digital Democracy. Princeton University Press.

Holman, Mirya R. and J. Celeste Lay. 2019. "They See Dead People (Voting): Correcting Misperceptions about Voter Fraud in the 2016 U.S. Presidential Election." Journal of Political Marketing 18(1-2): 31-68.

Hopkins, Daniel J. and Jonathan M. Ladd. 2014. "The Consequences of Broader Media Choice: Evidence from the Expansion of Fox News." Quarterly Journal of Political Science 9(1): 115-135.

Hovland, Carl, Irving Janis and Harold Kelley. 1953. Communication and Persuasion. Yale University Press.

Hovland, Carl and Walter Weiss. 1951. "The Influence of Source Credibility on Communication Effectiveness." Public Opinion Quarterly 15(4): 635-650.

Iyengar, Shanto and Kyu S. Hahn. 2009. "Red Media, Blue Media: Evidence of Ideological Selectivity in Media Use." Journal of Communication 59(1), 19-39.

Jungherr, Andrea, Alexander Wuttke, Matthias Mader and Harald Schoen. 2021. "A Source Like Any Other? Field and Survey Experiment Evidence on How Interest Groups Shape 
Public Opinion." Journal of Communication 71(2): 276-304.

Jurkowitz, Mark, Amy Mitchell, Elisa Shearer, and Mason Walker. 2020. "U.S. Media Polarization and the 2020 Election: A Nation Divided." Pew Research Center Report. https: //www.journalism.org/2020/01/24/u-s-media-polarization-and-the-2020-electiona-nation-divided/

Kam, Cindy D. and Elizabeth J. Zechmeister. 2013. "Name Recognition and Candidate Support." American Journal of Political Science 57(4): 971-986.

Kim, Young Mie, Jordan Hus, David Neiman, Colin Kou, Levi Bankston, Soo Yun Kim, Richard Heinrich, Robyn Baragwanath and Garvesh Raskutti. 2018. "The Stealth Media? Groups and Targets behind Divisive Issue Campaigns on Facebook." Political Communication 35(4): 515-541.

Ladd, Jonathan. 2010. "The Role of Media Distrust in Partisan Voting." Political Behavior 32(4): $567-585$.

Ladd, Jonathan. 2012. Why Americans Hate the Media and How it Matters. Princeton University Press.

Lazer, David M., Matthew A. Baum, Yochai Benkler, Adam J. Berinsky, Kelly M. Greenhill, Filippo Menezer, Miriam J. Metzger, Brendan Nyhan, Gordon Pennycook, David Rothschild, Michael Schudson, Steven A. Sloman, Cass R. Sunstein, Emily A. Thorson, Duncan J. Watts and Jonathan L. Zittrain. 2018. "The Science of Fake News." Science 359 (6380): 1094-1096

Levendusky, Matthew. 2013. How Partisan Media Polarize America. University of Chicago Press.

Levendusky, Matthew and Neil Malhotra. 2016. "Does Media Coverage of Partisan Polarization Affect Political Attitudes?" Political Communication 33(2): 283-301.

Levy, Ro'ee. 2021. "Social Media, News Consumption and Polarization: Evidence from a Field Experiment." American Economic Review 111(3): 831-870.

Lubbers, Eric. 2016. "These is no such thing as the Denver Guardian, despite that Facebook 
post you saw." Denver Post. November 5, 2016. https://www.denverpost.com/2016/ 11/05/there-is-no-such-thing-as-the-denver-guardian/

Luca, Mario, Kevin Munger, Jonathan Nagler and Joshua A. Tucker. ND. "You Won't Believe Our Results! But They Might: Heterogeneity in Beliefs about the Accuracy of Online Media." Journal of Experimental Political Science

Lupia, Arthur and Matthew McCubbins. 1998. The Democratic Dilemma. Cambridge University Press.

Mahone, Jessica and Philip Napoli. 2020. "Hundreds of Hyperpartisan Sites are Masquerading as Local News." Nieman Lab July 13, 2020. https://www.niemanlab.org/2020/07/ hundreds-of-hyperpartisan-sites-are-masquerading-as-local-news-this-map-showsif-theres-one-near-you/

Martin, Gregory J. and Joshua McCrain. 2019. "Local News and National Politics." American Political Science Review 113(2): 372-384.

Martin, Gregory J. and Ali Yurukoglu. 2017. "Bias in Cable News: Persuasion and Polarization." American Economic Review 107(9): 2565-2599.

Messing, Solomon and Sean J. Westwood. 2014. "Selective Exposure in the Age of Social Media." Communication Research 41(8), 1042-1063.

Metzger, Miriam J., Andrew J. Flanagin and Ryan B. Medders. 2010. "Social and Heuristic Approaches to Credibility Evaluation Online." Journal of Communication 60(3): 413-439.

Metzger, Miriam J., and Andrew J. Flanagin, Keren Eyal, Daisy R. Lemus and Robert M. McCann. 2003. "Credibility for the 21st Century: Integrating Perspectives on Source, Message, and Media Credibility in the Contemporary Media Environment." Annals of the International Communication Association 27(1): 293-335.

Miller, Joanne M. and Jon A. Krosnick. 2000. "News Media Impact on the Ingredients of Presidential Evaluations." American Journal of Political Science 44(2): 301-315.

Mosleh, Mohsen, Gordon Pennycook, Antonio A. Archar and David G. Rand. 2021. "Cognitive Reflection Correlates With Behavior on Twitter." Nature Communications 12: 921. 
Mondak, Jeffrey. 1993. "Source Cues and Policy Approval." American Journal of Political Science 37(1): 186-212.

Mullainathan, Sendhil and Andrei Shleifer. 2005. "The Market for News." American Economic Review 95(4): 1031-1053.

Mummolo, Jonathan. 2016. "News from the Other Side: How Topic Relevance Limits the Prevalence of Partisan Selective Exposure." Journal of Politics 78(3), 763-773.

Mummolo, Jonathan and Erik Peterson. 2019. "Demand Effects in Survey Experiments: An Empirical Assessment." American Political Science Review 113(2): 517-529.

Munger, Kevin. 2020. "All the News That's Fit to Click: The Economic of Clickbait Media." Political Communication 37(3): 376-397.

Mutz, Diana C. and Paul S. Martin. 2001. "Facilitating Communication Across Lines of Political Difference: The Role of Mass Media." American Political Science Review 95(1): $97-114$.

Mutz, Diana C. and Lori Young. 2011. "Communication and Public Opinion." Public Opinion Quarterly 75(5): 1018-1044.

Pennycook, Gordon and David G. Rand. 2019. "Fighting Misinformation on Social Media Using Crowdsourced Judgments of News Source Quality." Proceedings of the National Academy of Sciences 116(7): 2521-2526.

Peterson, Erik. 2021. "Not Dead Yet: Political Learning from Newspapers in a Changing Media Landscape." Political Behavior 43(1): 339-361.

Peterson, Erik and Ali Kagalwala. 2021. "When Unfamiliarity Breeds Contempt: How Partisan Selective Exposure Sustains Oppositional Media Hostility." American Political Science Review 115(2): 585-598.

Peterson, Erik and Shanto Iyengar. 2021. "Partisan Gaps in Political Information and Information-Seeking Behavior: Motivated Reasoning or Cheerleading?" American Journal of Political Science 65(1): 133-147.

Peterson, Erik, Sharad Goel and Shanto Iyengar. 2021. "Partisan Selective Exposure in 
Online News Consumption." Political Science Research \& Methods 9(2): 242-258.

Petty, Richard E. and John T. Cacioppo. 1986. Communication and Persuasion. Springer. Pornpitakpan, Chanthika. 2004. "The Persuasiveness of Source Credibility: A Critical Review of Five Decades' Evidence." Journal of Applied Social Psychology 34(2): 243-281. Prior, Markus. 2007. Post-Broadcast Democracy. Cambridge University Press.

Rainey, Carlisle. 2014. "Arguing for a Negligible Effect." American Journal of Political Science 58(4): 1083-1091.

Ryan, Timothy and Amanda Aziz. 2021. "Is the Political Right More Credulous: Experimental Evidence Against Asymmetric Motivations to Believe False Political Information." Journal of Politics 83(3): 1168-1172.

Stubbs, Jack and Ginger Gibson. 2017. "Russia's RT America registers as 'foreign agent' in U.S." Reuters. November 13, 2017. https://www.reuters.com/article/us-russiausa-media-restrictions-rt/russias-rt-america-registers-as-foreign-agent-inu-s-idUSKBN1DD25B

Sundar, S. Shyam. 2008. "The MAIN Model: A Heurstic Approach to Understanding Technology Effects on Credibility." in Digitial Media, Youth and Credibility. (Eds. Miriam J. Metzger and Andrew J. Flanagin). Pages 73-100. MIT Press.

Sterrett, David, Dan Malato, Jennifer Benz, Liz Kantor, Trevor Tompson, Tom Rosenstiel, Jeff Sonderman and Kevin Loker. 2019. "Who Shared It? Deciding What News to Trust on Social Media." Digital Journalism 7(6): 783-801.

Stroud, Natalie. 2011. Niche News: The Politics of News Choice. Oxford University Press.

Stroud, Natalie. 2008. "Media Use and Political Predispositions: Revisiting the Concept of Selective Exposure." Political Behavior 30(3): 341-366.

Tsafi, Yariv and Joseph N. Capella. 2003. "Do People Watch What They Do Not Trust?" Communication Research 30(5): 504-529.

Tyler, Matthew, Justin Grimmer and Shanto Iyengar. ND. "Partisan Enclaves and Information Bazaars: Mapping Selective Exposure to Online News." Journal of Politics 
Forthcoming.

Van Aelst, Peter, Jesper Strömbäck, Toril Aalberg, Frank Esser, Claes de Vreese, Jörg Matthes, David Hopmann, Susana Salgado, Nicolas Hubé, Agnieszka Stepińska, Stylianos Papathanassoupoulos, Rosa Berganza, Guido Legante, Carsten Reinemann, Tamir Sheafer and James Stanyer. "Political Communication in a High-Choice Media Environment: A Challenge for Democracy?" 2017. Annals of the International Communication Association 41(3): $3-27$.

Weber, Christopher, Johanna Dunaway and Tyler Johnson. 2012. "It's All in the Name: Source Cue Ambiguity and the Persuasive Appeal of Campaign Ads." Political Behavior 34: $561-584$.

Weisbuch, Max, Diana M. Mackie and Teresa Garcia-Marques. 2003. "Prior Source Exposure and Persuasion." Personality and Social Psychology Bulletin 29(6): 691-700.

Zaller, John R. 1992. The Nature and Origins of Mass Opinion. Cambridge University Press. 


\title{
Supporting Information for: "The Influence of Unknown Media on Public Opinion"
}

\author{
Erik Peterson and Maxwell B. Allamong \\ Texas A\&M University \\ Department of Political Science
}




\section{Contents}

\begin{tabular}{ll}
\hline A Appendix A: Survey Information & 1
\end{tabular}

A.1 Research Ethics . . . . . . . . . . . . . . . . . . . . . . . . . . . . . . 1

A.2 Survey Demographics . . . . . . . . . . . . . . . . . . . . . . . . . 1

A.3 News Source Familiarity and Reputations. . . . . . . . . . . . . . . . . 1

A.4 Study 1 Dependent Variables . . . . . . . . . . . . . . . . . . 5

A.5 Study 2 Dependent Variables . . . . . . . . . . . . . . . . . 5

A.6 Study 3 Dependent Variables $\ldots \ldots \ldots$. . . . . . . . . . . . . 6

A.7 Study 4 Dependent Variables . . . . . . . . . . . . . . . . . . . . . 6

A.8 Study 5 Dependent Variables . . . . . . . . . . . . . . . . . . . . 7

A.9 Covariates in the Analysis $\ldots \ldots \ldots \ldots \ldots \ldots \ldots$

\begin{tabular}{ll}
\hline B Appendix B: Experimental Materials & 9
\end{tabular}

B.1 State-Specific Information . . . . . . . . . . . . . . . . . 9

B.2 News Reputations/News Selection . . . . . . . . . . . . . . . . . 10

B.3 News Articles . . . . . . . . . . . . . . . . . . . . . . . . . . . . . . . . 11

B.3.1 Study 1 and Study $4 \ldots \ldots \ldots$

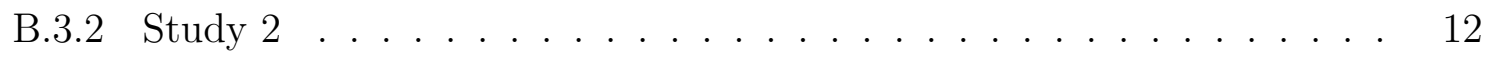

B.3.3 Study $3 \ldots \ldots \ldots \ldots$

B.3.4 Study $5 \ldots \ldots \ldots \ldots \ldots$

\begin{tabular}{lll}
\hline C Appendix C: Supplemental Experimental Analyses & 13
\end{tabular}

C.1 Respondent Attention . . . . . . . . . . . . . . . . . . . 13

C.2 Tabular Results . . . . . . . . . . . . . . . . . . . . . . . . . . 13

C.3 Self-Reported Familiarity as a Moderating Variable . . . . . . . . . . . 16

C.4 Conditional Effects Among Entertainment Seekers . . . . . . . . . . . . . 17 
\begin{tabular}{|l|l|}
\hline D Appendix D: Supplemental News Choice/News Trust Analyses & 19
\end{tabular}

D.1 Source Selection By Choice Task ．.. . . . . . . . . . . . . . . . . . . 19

D.2 Trust in Unfamiliar News Sources . . . . . . . . . . . . . . . . . 20

D.3 Trust and Unfamiliar Source News Use . . . . . . . . . . . . . . . . 21 


\section{A Appendix A: Survey Information}

\section{A.1 Research Ethics}

This research project was declared exempt under Category 2 of the common rule by Texas A\&M's Institutional Review Board. With respect to APSA Principles and Guidance, respondents were provided with an information sheet describing the survey and could choose whether or not to proceed, with consent indicated by agreeing to continue with the survey. Their participation was voluntary and respondents could break off their participation at any point during the survey. Respondents were compensated for their participation in the survey, with compensation determined by the survey provider (Lucid).

Research documentation and data that support the findings of this study are openly available in the APSR Dataverse at: https://doi.org/10.7910/DVN/DIU0M1.

\section{A.2 Survey Demographics}

Tables A1 and A2 display the demographics of respondents in the two surveys. In both cases the samples were drawn from a panel maintained by Lucid to match nationally representative quotas for age, ethnicity, gender and geographic location. While they remain convenience samples, the surveys provide a diverse set of respondents on which to examine the effects of unfamiliar and familiar news sources.

\section{A.3 News Source Familiarity and Reputations}

Table A3 shows the share of the sample that indicated they had heard of each news source used in the study. When they were asked this question they were presented with a checklist of news options that showed the logo and name of each news source.

The news outlets with bold names were used in the "familiar source" treatment conditions and have high levels of familiarity. The news outlets with names in italics were used in the "unfamiliar source" treatment conditions and have low levels of awareness. 
Table A1: Survey 1 Demographics

\begin{tabular}{rr}
\hline & Share in Category \\
\hline Black (Non-Hispanic) & 0.11 \\
Hispanic & 0.11 \\
White (Non-Hispanic) & 0.68 \\
Other Race & 0.10 \\
College Plus & 0.45 \\
Female & 0.52 \\
Age & 46.09 \\
Income & 66045.95 \\
Democrat & 0.49 \\
Republican & 0.36 \\
Independent & 0.16 \\
\hline Sample Size & 6042 \\
\hline
\end{tabular}

Table A2: Survey 2 Demographics

\begin{tabular}{rr}
\hline & Share in Category \\
\hline Black (Non-Hispanic) & 0.10 \\
Hispanic & 0.11 \\
White (Non-Hispanic) & 0.69 \\
Other Race & 0.09 \\
College Plus & 0.44 \\
Female & 0.52 \\
Age & 46.46 \\
Income & 65202.48 \\
Democrat & 0.50 \\
Republican & 0.35 \\
Independent & 0.16 \\
\hline Sample Size & 5068 \\
\hline
\end{tabular}

The far right column shows a comparison for the news outlets where source awareness was also measured using similar questions by the Pew Research Center in its "U.S. Media Polarization and the 2020 Election Report", which was based on a nationally representative survey of the public in conducted in late 2019. Reassuringly, this shows the measures of source familiarity in the two surveys we use are highly similar to those observed by Pew.

We also consider trust in these news outlets among various groups in the below tables. Source 
Table A3: Media Source Familiarity

\begin{tabular}{l|c|c|c}
\hline News Source & $\begin{array}{c}\text { Share Aware of Source } \\
(\text { Jan 2021) }\end{array}$ & $\begin{array}{c}\text { Share Aware of Source } \\
\text { (June 2021) }\end{array}$ & $\begin{array}{c}\text { Share Aware of Source } \\
\text { (Pew 2019) }\end{array}$ \\
\hline Fox News & 0.90 & 0.91 & 0.94 \\
New York Times & 0.85 & 0.86 & 0.83 \\
USA Today & 0.81 & 0.84 & 0.85 \\
Local Newspaper & 0.76 & 0.73 & - \\
Huffington Post & 0.63 & 0.61 & 0.63 \\
Fake Local Website & 0.35 & 0.39 & - \\
Partisan Local Website & 0.22 & 0.18 & - \\
Non-Profit Local Website & 0.16 & 0.12 & - \\
RT & 0.10 &
\end{tabular}

trust was measured on a 5-point scale from 1 ("Not at all trustworthy") to 5 ("Extremely Trustworthy"). We re-code this measure to lie between 0 and 1 . We separately display the average trust in various media sources for all respondents (column 1), only those respondents who had earlier indicated they were familiar with the news source (column 2), Democrats (column 3) and Republicans (column 4).

Table A4: Media Source Trust Among Different Groups (Survey 1)

\begin{tabular}{lrrrr}
\hline News Source & All & Aware of Source & Democrats & Republicans \\
\hline Local Newspaper & 0.52 & 0.54 & 0.61 & 0.43 \\
New York Times & 0.50 & 0.50 & 0.64 & 0.33 \\
USA Today & 0.48 & 0.48 & 0.56 & 0.38 \\
Partisan Local Website & 0.47 & 0.59 & 0.51 & 0.43 \\
Fake Local Website & 0.47 & 0.55 & 0.52 & 0.42 \\
Non-Profit Local Website & 0.45 & 0.58 & 0.49 & 0.40 \\
Huffington Post & 0.44 & 0.43 & 0.53 & 0.33 \\
Fox News & 0.38 & 0.38 & 0.32 & 0.46 \\
RT & 0.37 & 0.39 & 0.40 & 0.34 \\
\hline
\end{tabular}


Table A5: Media Source Trust Among Different Groups (Survey 2)

\begin{tabular}{lrrrr}
\hline News Source & All & Aware of Source & Democrats & Republicans \\
\hline New York Times & 0.52 & 0.52 & 0.66 & 0.35 \\
Local Newspaper & 0.52 & 0.53 & 0.61 & 0.43 \\
USA Today & 0.51 & 0.51 & 0.61 & 0.39 \\
Partisan Local Website & 0.48 & 0.62 & 0.55 & 0.43 \\
Fake Local Website & 0.48 & 0.57 & 0.55 & 0.42 \\
Huffington Post & 0.46 & 0.46 & 0.56 & 0.34 \\
Non-Profit Local Media & 0.46 & 0.61 & 0.52 & 0.40 \\
Fox News & 0.44 & 0.44 & 0.40 & 0.51 \\
$R T$ & 0.38 & 0.51 & 0.44 & 0.33 \\
\hline
\end{tabular}

Two points emerge from this consideration that are important for interpreting our findings. First, local newspapers and USA Today, the sources used in the "Familiar" conditions of our experiments, are among the highest in trust across those considered in the study. To the extent there are other options with higher levels of trust among some groups, they tend to be highly polarizing (e.g., New York Times for Democrats and Fox News for Republicans). Second, while the sources used in the "Unfamiliar" conditions are lower in trust than others, they do not suffer much of a penalty. The fictional news website used in Study 3 is among the most trusted, least polarizing sources in the study indicating the relatively charitable interpretation that respondents take in evaluating such media. We see this intersection of declining trust in mainstream news sources and charitable interpretations of how trustworthy unknown news sources are as explaining our findings

Using an item that was only included in the first of our surveys, we also consider the perceived bias of these different sources. This measure used a seven-point scale from 1 ("Extremely conservative") to 4 ("Moderate; middle of the road") to 7 ("Extremely liberal"). We recode this variable to lie between 0 and 1 . The familiar mainstream news sources, with the exception of Fox News, are generally rated as having a liberal bias. These ratings are driven largely by perceptions of liberal bias in media coverage among Republicans. Again, consistent 
with our findings in the main text the unfamiliar news sources are evaluated closest to the neutral mid-point of the scale.

Table A6: Perceived Media Bias Among Different Groups (Survey 1)

\begin{tabular}{lrrrr}
\hline News Source & All & Aware of Source & Democrats & Republicans \\
\hline New York Times & 0.65 & 0.66 & 0.59 & 0.74 \\
Huffington Post & 0.62 & 0.66 & 0.59 & 0.68 \\
USA Today & 0.59 & 0.60 & 0.55 & 0.66 \\
Local Newspaper & 0.58 & 0.59 & 0.55 & 0.62 \\
Non-Profit Local Website & 0.55 & 0.55 & 0.52 & 0.58 \\
Fake Local Website & 0.54 & 0.54 & 0.51 & 0.58 \\
RT & 0.53 & 0.50 & 0.48 & 0.60 \\
Partisan Local Website & 0.51 & 0.52 & 0.49 & 0.54 \\
Fox News & 0.35 & 0.34 & 0.30 & 0.41 \\
\hline
\end{tabular}

\section{A.4 Study 1 Dependent Variables}

The first principal component of these items explains $51 \%$ of the variance in these outcome measures. We standardize this measure to have mean zero and standard deviation one for the analysis. Higher values indicate more dissatisfaction with state tax policy (i.e., that the state taxes are overly burdensome and should be reduced).

Table A7: State Tax Policy - PCA Loadings

\begin{tabular}{ll}
\hline Survey Item & PC1 Loading \\
\hline Satisfaction with tax system in state (5-pt scale) & -0.52 \\
Raise Taxes/Cut Spending to address budget deficit (101-pt scale) & -0.31 \\
Taxes pushing residents to breaking point (7-pt scale) & 0.40 \\
Taxes low/high in state (3-pt scale) & 0.47 \\
Approval of state tax policy mentioned in article (5-pt scale) & -0.51 \\
\hline
\end{tabular}

\section{A.5 Study 2 Dependent Variables}

The first principal component of these items explains $50 \%$ of the variance in these outcome measures. We standardize this measure to have mean zero and standard deviation one for the analysis. Higher values indicate more pessimistic views of American politics (i.e., more perceived polarization/gridlock, less expected future progress). 
Table A8: Perceived Polarization/Gridlock/Pessimism - PCA Loadings

\begin{tabular}{ll}
\hline Survey Item & PC1 Loading \\
\hline Progress in next 4 years-Improving America's Image (5-pt scale) & -0.42 \\
Progress in next 4 years-Improving Economy (5-pt scale) & -0.42 \\
Progress in next 4 years-Changing Partisan Tone (5-pt scale) & -0.42 \\
Optimism about U.S. Future (4-pt scale) & -0.38 \\
Common ground for Dems and Reps (5-pt scale) & -0.30 \\
Expect improved relations for Reps and Dems (3-pt scale) & -0.37 \\
Domestic enemies biggest threat to American way of life (1/0) & 0.07 \\
Dems and Reps want to do what is right for country (5-pt scale) & -0.30 \\
\hline
\end{tabular}

\section{A.6 Study 3 Dependent Variables}

The first principal component of these items explains $75 \%$ of the variance in these outcome measures. We standardize this measure to have mean zero and standard deviation one for the analysis. Higher values indicate more confidence in the integrity of the 2020 presidential election and lower perceptions of voter fraud.

Table A9: Perceptions of Voter Fraud - PCA Loadings

\begin{tabular}{ll}
\hline Survey Item & PC1 Loading \\
\hline Disagree: Millions of illegal votes cast in 2020 (10-pt scale) & 0.44 \\
Confidence election was fair (5-pt scale) & 0.48 \\
Confidence Biden won 2020 election (101-pt scale) & 0.46 \\
2020 election was secure (7-pt scale) & 0.44 \\
Disagree: Voting in US prone to fraud (7-pt scale) & 0.42 \\
\hline
\end{tabular}

\section{A.7 Study 4 Dependent Variables}

The first principal component of these items explains $48 \%$ of the variance in these outcome measures. We standardize this measure to have mean zero and standard deviation one for the analysis. Higher values indicate more dissatisfaction with state tax policy (i.e., that the state taxes are overly burdensome and should be reduced). 
Table A10: State Tax Policy - PCA Loadings

\begin{tabular}{ll}
\hline Survey Item & PC1 Loading \\
\hline Satisfaction with tax system in state (5-pt scale) & -0.54 \\
Raise Taxes/Cut Spending to address budget deficit (101-pt scale) & -0.34 \\
Taxes pushing residents to breaking point (7-pt scale) & 0.32 \\
Taxes low/high in state (3-pt scale) & 0.45 \\
Approval of state tax policy mentioned in article (5-pt scale) & -0.52 \\
\hline
\end{tabular}

\section{A.8 Study 5 Dependent Variables}

The first principal component of these items explains $52 \%$ of the variance in these outcome measures. We standardize this measure to have mean zero and standard deviation one for the analysis. Higher values indicate greater perceptions of the threat and costs of cyber attacks in the United States.

Table A11: Cyber Attack Threat - PCA Loadings

\begin{tabular}{ll}
\hline Survey Item & PC1 Loading \\
\hline Concern about cyberattacks-US Government (4-pt scale) & 0.51 \\
Concern about cyberattacks-US Business(4-pt scale) & 0.51 \\
Cyberattacks pose major risk to US economy (7-pt scale) & 0.48 \\
Threat of cyberattacks to US interests (3-pt scale) & 0.48 \\
US preparation to prevent cyberattacks(4-pt scale) & -0.12 \\
\hline
\end{tabular}

\section{A.9 Covariates in the Analysis}

To increase the precision of the effect estimates in our studies, our pre-analysis plans specified a variety of pre-treatment covariates that would predict a study's dependent variable to include in the regressions used to estimate treatment effects.

Across all the studies, we include a three-point partisanship item separating Republicans (and those leaning towards the Republican party), "Pure" independents and Democrats (and those leaning towards the Democratic party) as a covariate. This was previously measured by Lucid and passed into the survey. This agrees with a partisanship measure from 
the end of our survey in $93 \%$ of cases.

The other studies included additional covariates. In Study 2 we also include a respondent's level of affective polarization (the absolute difference in their feeling thermometer ratings of the Democratic and Republican parties). For Study 3 we include a respondent's relative feeling thermometer rating of Donald Trump compared to Joe Biden as a covariate. For Study 4 we include a pre-treatment measure of the respondent's overall views on taxation in the United States. Finally, in Study 5 we include a measure of the respondent's concerns about cyber attacks measured at the beginning of the survey. 


\section{B Appendix B: Experimental Materials}

\section{B.1 State-Specific Information}

Respondents were assigned media and tax treatments based on their state of residence, which they reported at the beginning of the survey. This ensures the local media source and policy discussion are relevant for them. When evaluating local media outlets they saw a menu of options that included a large newspaper from their state, a local partisan website for their state and a non-profit news organization from their state. These options also included a fictional newspapers for each state, created using common newspaper names (i.e., "Times", "Tribune" or "News"), but chosen so the fictional newspaper's name did not resemble any of the area's actual major media sources. These options are listed in Table B1. 
Table B1: Local Media Sources for Each State

\begin{tabular}{|c|c|c|c|c|}
\hline State & State Newspaper & Local Partisan Website & Fictional State Newspaper & State Non-Profit Media \\
\hline Alabama & The Birmingham News & Alabama Business Daily & Alabama Tribune & Birmingham Watch \\
\hline Alaska & Alaska Dispatch News & Alaska Business News & Alaska Times & CoastAlaska \\
\hline Arizona & Arizona Republic & Arizona Business Daily & Arizona Times & Arizona Center for Investigative Reporting \\
\hline Arkansas & Arkansas Democrat-Gazette & Arkansas Business Daily & Arkansas Tribune & Arkansas Nonprofit news network \\
\hline California & Los Angeles Times & California Business Daily & California Tribune & CALmatters \\
\hline Colorado & The Denver Post & Colorado Business Daily & Colorado Tribune & The Colorado Independent \\
\hline Connecticut & Hartford Courant & Connecticut Business Daily & Connecticut Tribune & The Connecticut Mirror \\
\hline Delaware & The News-Journal (Wilmington) & Delaware Business Daily & Delaware Tribune & Delaware Public Media \\
\hline Florida & Tampa Bay Times & Florida Business Daily & Florida News & Florida Bulldog \\
\hline Georgia & The Atlanta Journal-Constitution & Georgia Business Daily & Georgia Tribune & Georgia News Lab \\
\hline Hawaii & Honolulu Star-Advertiser & Hawaii Business Daily & Hawaii Times & Honolulu Civil Beat \\
\hline Idaho & Idaho Statesmen & Idaho Business Daily & Idaho News & Boise Dev \\
\hline Illinois & The Chicago Tribune & Illinois Business Daily & Illinois News & ProPublica Illinois \\
\hline Indiana & The Indianapolis Star & Indiana Business Daily & Indiana Tribune & WFYI \\
\hline Iowa & The Des Moines Register & Iowa Business Daily & Iowa Times & Iowa Watch \\
\hline Kansas & The Wichita Eagle & Kansas Business Daily & Kansas Tribune & The Beacon \\
\hline Kentucky & The Courier-Journal & Kentucky Business Daily & Kentucky Times & KyCIR \\
\hline Louisiana & The Advocate & Louisiana Business Daily & Louisiana Times & The Lens \\
\hline Maine & Portland Press Herald & Maine Business Daily & Maine Times & The Maine Monitor \\
\hline Maryland & The Baltimore Sun & Maryland Business Daily & Maryland Tribune & The Baltimore Brew \\
\hline Massachusetts & The Boston Globe & Massachusetts Business Daily & Massachusetts Times & The Bedford Citizen \\
\hline Michigan & Detroit Free Press & Michigan Business Daily & Michigan Times & East Lansing Info \\
\hline Minnesota & The Minneapolis Star Tribune & Minnesota Business Daily & Minnesota Times & MinnPost \\
\hline Mississippi & The Clarion-Ledger & Mississippi Business Daily & Mississippi Times & Mississippi Free Press \\
\hline Missouri & St. Louis Post-Dispatch & Missouri Business Daily & Missouri Herald & The Beacon \\
\hline Montana & Billings Gazette & Montana Business Daily & Montana Times & Montana Free Press \\
\hline Nebraska & Omaha World-Herald & Nebraska Business Daily & Nebraska Times & The Reader \\
\hline Nevada & Las Vegas Review-Journal & Nevada Business Daily & Nevada Tribune & The Nevada Independent \\
\hline New Hampshire & New Hampshire Union Leader & New Hampshire Business Daily & New Hampshire Times & InDepthNH \\
\hline New Jersey & Star Ledger & New Jersey Business Daily & New Jersey Times & NJ Spotlight News \\
\hline New Mexico & Albuquerque Journal & New Mexico Business Daily & New Mexico Tribune & Searchlight New Mexico \\
\hline New York & The Buffalo News & New York Business Daily & New York Tribune & ProPublica \\
\hline North Carolina & The Charlotte Observer & North Carolina Business Daily & North Carolina News & Carolina Public Press \\
\hline North Dakota & Bismarck Tribune & North Dakota Business Daily & North Dakota Times & MinnPost \\
\hline Ohio & Cleveland Plain Dealer & Ohio Business Daily & Ohio Times & Eye on Ohio \\
\hline Oklahoma & The Oklahoman & Oklahoma Business Daily & Oklahoma Tribune & Oklahoma Watch \\
\hline Oregon & The Oregonian & Oregon Business Daily & Oregon Times & Underscore \\
\hline Pennsylvania & The Philadelphia Inquirer & Pennsylvania Record & Pennsylvania Times & Spotlight PA \\
\hline Rhode Island & Providence Journal & Rhode Island Business Daily & Rhode Island Tribune & East Greenwich News \\
\hline South Carolina & The Post and Courier & Palmetto Business Daily & South Carolina Tribune & The Nerve \\
\hline South Dakota & Argus Leader & South Dakota Business Daily & South Dakota Times & South Dakota News Watch \\
\hline Tennessee & Knoxville News Sentinel & Tennessee Business Daily & Tennessee Times & Tennessee Lookout \\
\hline Texas & Houston Chronicle & Texas Business Daily & Texas Times & The Texas Tribune \\
\hline Utah & The Salt Lake Tribune & Utah Business Daily & Utah Times & Utah Investigative Journalism Project \\
\hline Vermont & Burlington Free Press & Vermont Business Daily & Vermont Tribune & The Vermont Digger \\
\hline Virginia & The Virginian-Pilot & Virginia Business Daily & Virginia Tribune & Charlottesville Tomorrow \\
\hline Washington & The Seattle Times & Washington Business Daily & Washington Tribune & Investigative Watch \\
\hline West Virginia & Charleston Gazette-Mail & West Virginia Business Daily & West Virginia Tribune & Mountain State Spotlight \\
\hline Wisconsin & Milwaukee Journal Sentinel & Wisconsin Business Daily & Wisconsin Times & Wisconsin Watch \\
\hline Wyoming & Casper Star-Tribune & Wyoming Business Daily & Wyoming Times & WyoFile \\
\hline
\end{tabular}

\section{B.2 News Reputations/News Selection}

When evaluating the media sources or selecting information sources in the patient preference

tasks that preceded the experimental treatments in each study, respondents saw the name

of the media outlet as well as its logo. Below is an example of how this looked for Texas

respondents when evaluating local media. 
Figure B1: Example of Local News Options

\section{Please click on all of the news sources that you have heard of, regardless of whether you use them or not.}

\section{If you are unsure about a source, please DO NOT click it.}

HOUSTON $\rtimes$ CHRONICLE

Houston Chronicle

\section{שexas đimes}

Texas Times

\section{Texas Business Daily}

Texas Business Daily

因THE TEXAS TRIBUNE

Texas Tribune

The local newspaper, partisan local news website and non-profit news website all used the news outlet's real logo. For the fictional local news website, the logo was simply the outlet's name in a script text.

\section{B.3 News Articles}

\section{B.3.1 Study 1 and Study 4}

For Study 1 and Study 4, those in the article conditions read a tax policy treatment that mentioned the worst performing part of a state's tax system based on a study by the Tax Foundation's "2020 State Business Tax Climate Index." The components that received ratings were: property, sales, corporate and income taxes. This was used to make a broader critique of tax policy in the state, based on a June 2020 article from the Hawkeye Reporter, a website on the list of hyper-partisan online local media produced by Mahone and Napoli (2020) titled "Tax Relief Advocate: Iowa Can't Expect Taxpayers to Keep Shouldering 
Heavy Loads." Link.

\section{B.3.2 Study 2}

For Study 2, the article discussed Joe Biden's inauguration and noted the problems facing the administration while emphasizing how polarization would limit progress on these issues. It combined elements of articles that had appeared on RT titled "Joe Biden sworn in as 46th US president, taking helm of embattled \& divided nation." Link , "Tired of the political divide in America? Don't Worry, it's going to get much worse" Link and "Poll finds just 15\% of Americans confident in US democracy as partisan divisions only grow ahead of presidential vote" Link.

\section{B.3.3 Study 3}

For Study 3 the article corrected false claims of widespread voter fraud in the 2020 Presidential election. It was a shortened version of an Associated Press story titled "Explainer: Election claims, and why it's clear Biden won" Link.

\section{B.3.4 Study 5}

For Study 5 the article discussed the substantial costs of cyber attacks for the US economy, noting the variety of risks that they posed to the energy sector and financial institutions. The article also emphasized the US government's inability to prevent recent attacks. It combined elements of articles that appeared on RT titled "Oil Pipeline Cyberattack Exposes America's Multi-Trillion Dollar Infrastructure Security Crisis" Link and "Fed Chair Warns Cyberattacks Pose Biggest Threat to US Economy" Link. 


\section{Appendix C: Supplemental Experimental Analyses}

\section{C.1 Respondent Attention}

Each of surveys included a pre-treatment attention check. Respondents who did not successfully pass the attention check were not allowed to continued with the survey. We also included a post-treatment attention check that asked respondents in the treatment conditions to report the source of the news article they read.

Below we separate out the results of the post-treatment manipulation check by study. Respondents are counted as correct if they identified the source of the article they read in the manipulation check from a list of four to five options.

Table C1: Manipulation Check Results

\begin{tabular}{lc}
\hline Study & Share Correct \\
\hline Study 1 & $71 \%$ \\
Study 2 & $76 \%$ \\
Study 3 & $74 \%$ \\
Study 4 & $68 \%$ \\
Study 5 & $80 \%$ \\
\hline
\end{tabular}

While the results in the studies with unfamiliar local media sources are lower, this appears to mostly stem from respondent's misidentifying one of the unfamiliar news sources as the other. In Studies 1, 3 and 4 those assigned to the familiar local media conditions were correct $77-81 \%$ of the time in the attention checks.

\section{C.2 Tabular Results}

Table C2 displays the tabular results used to produce Figure 1 in the main text. 
Table C2: Effects of Familiar and Unfamiliar Sources on Opinion

\begin{tabular}{|c|c|c|c|c|c|}
\hline & 1 & 2 & 3 & 4 & 5 \\
\hline Intercept & $\begin{array}{r}-0.31^{*} \\
(0.03)\end{array}$ & $\begin{array}{c}-0.71^{*} \\
(0.03)\end{array}$ & $\begin{array}{r}-0.25^{*} \\
(0.02)\end{array}$ & $\begin{array}{r}-0.27^{*} \\
(0.04)\end{array}$ & $\begin{array}{r}-3.25^{*} \\
(0.06)\end{array}$ \\
\hline Unfamiliar Source & $\begin{array}{c}0.13^{*} \\
(0.03)\end{array}$ & $\begin{array}{c}0.05 \\
(0.03)\end{array}$ & $\begin{array}{c}0.09^{*} \\
(0.02)\end{array}$ & $\begin{array}{c}0.17^{*} \\
(0.03)\end{array}$ & $\begin{array}{r}0.07^{*} \\
(0.03)\end{array}$ \\
\hline Familiar Source & $\begin{array}{c}0.21^{*} \\
(0.03)\end{array}$ & $\begin{array}{c}0.04 \\
(0.03)\end{array}$ & $\begin{array}{c}0.09^{*} \\
(0.02)\end{array}$ & $\begin{array}{c}0.17^{*} \\
(0.03)\end{array}$ & $\begin{array}{c}0.08^{*} \\
(0.03)\end{array}$ \\
\hline Independent & $\begin{array}{c}0.37^{*} \\
(0.04)\end{array}$ & $\begin{array}{r}0.84^{*} \\
(0.03)\end{array}$ & $\begin{array}{r}-0.09^{*} \\
(0.02)\end{array}$ & $\begin{array}{c}0.35^{*} \\
(0.04)\end{array}$ & $\begin{array}{r}-0.20^{*} \\
(0.03)\end{array}$ \\
\hline Republican & $\begin{array}{c}0.39^{*} \\
(0.03)\end{array}$ & $\begin{array}{c}1.11^{*} \\
(0.02)\end{array}$ & $\begin{array}{r}-0.10^{*} \\
(0.02)\end{array}$ & $\begin{array}{c}0.43^{*} \\
(0.03)\end{array}$ & $\begin{array}{r}-0.00 \\
(0.02)\end{array}$ \\
\hline Affective Polarization & & $\begin{array}{r}0.00^{*} \\
(0.00)\end{array}$ & & & \\
\hline Trump-Biden Therm & & & $\begin{array}{c}-0.01^{*} \\
(0.00)\end{array}$ & & \\
\hline Tax Views & & & & $\begin{array}{c}-0.01 \\
(0.01)\end{array}$ & \\
\hline Cyber Concern & & & & & $\begin{array}{c}0.91^{*} \\
(0.02)\end{array}$ \\
\hline$N$ & 6042 & 6042 & 6042 & 5068 & 5068 \\
\hline
\end{tabular}

We also consider several post-hoc analyses that were not included in our pre-analysis plan. In Tables C3 and C4 we consider heterogeneity in these results by separating out Democrats and Republicans. The only distinctions of note are that Republicans were not responsive to the perceived polarization treatment, from either news source, in Study 2 or from the unfamiliar source in Study 5. Across the rest of the studies, the results are similar when sub-setting within each political party. Among members of both parties, the effects of the familiar sources are larger than the effects of the unfamiliar source in Study 1 and the two sources have similarly sized effects in Study 3.

This suggests our findings generalize across partisans and whether or not the content encountered from the unfamiliar sources is ideologically congenial or pushes an uncongenial 
perspective.

Table C3: Effects of Familiar and Unfamiliar Sources on Opinion (Democrats)

\begin{tabular}{|c|c|c|c|c|c|}
\hline & 1 & 2 & 3 & 4 & 5 \\
\hline Intercept & $\begin{array}{r}-0.32^{*} \\
(0.03)\end{array}$ & $\begin{array}{r}-0.46^{*} \\
(0.04)\end{array}$ & $\begin{array}{r}-0.07^{*} \\
(0.02)\end{array}$ & $\begin{array}{r}-0.01 \\
(0.05)\end{array}$ & $\begin{array}{r}-3.07^{*} \\
(0.09)\end{array}$ \\
\hline Unfamiliar Source & $\begin{array}{c}0.14^{*} \\
(0.04)\end{array}$ & $\begin{array}{c}0.10^{*} \\
(0.03)\end{array}$ & $\begin{array}{c}0.07^{*} \\
(0.02)\end{array}$ & $\begin{array}{c}0.15^{*} \\
(0.05)\end{array}$ & $\begin{array}{c}0.10^{*} \\
(0.04)\end{array}$ \\
\hline Familiar Source & $\begin{array}{r}0.25^{*} \\
(0.04)\end{array}$ & $\begin{array}{c}0.09^{*} \\
(0.03)\end{array}$ & $\begin{array}{r}0.08^{*} \\
(0.02)\end{array}$ & $\begin{array}{c}0.19^{*} \\
(0.05)\end{array}$ & $\begin{array}{c}0.06 \\
(0.04)\end{array}$ \\
\hline Affective Polarization & & $\begin{array}{r}-0.00^{*} \\
(0.00)\end{array}$ & & & \\
\hline Trump-Biden Therm & & & $\begin{array}{r}-0.01^{*} \\
(0.00)\end{array}$ & & \\
\hline Tax Views & & & & $\begin{array}{r}-0.08^{*} \\
(0.01)\end{array}$ & \\
\hline Cyber Concern & & & & & $\begin{array}{c}0.86^{*} \\
(0.02)\end{array}$ \\
\hline$N$ & 2948 & 2948 & 2948 & 2515 & 2515 \\
\hline
\end{tabular}


Table C4: Effects of Familiar and Unfamiliar Sources on Opinion (Republicans)

\begin{tabular}{|c|c|c|c|c|c|}
\hline & 1 & 2 & 3 & 4 & 5 \\
\hline Intercept & $\begin{array}{c}0.10^{*} \\
(0.04)\end{array}$ & $\begin{array}{c}0.04 \\
(0.04)\end{array}$ & $\begin{array}{r}-0.31^{*} \\
(0.02)\end{array}$ & $\begin{array}{r}-0.30^{*} \\
(0.09)\end{array}$ & $\begin{array}{r}-3.52^{*} \\
(0.11)\end{array}$ \\
\hline Unfamiliar Source & $\begin{array}{c}0.11^{*} \\
(0.05)\end{array}$ & $\begin{array}{c}0.03 \\
(0.05)\end{array}$ & $\begin{array}{c}0.14^{*} \\
(0.03)\end{array}$ & $\begin{array}{c}0.19^{*} \\
(0.06)\end{array}$ & $\begin{array}{r}-0.05 \\
(0.05)\end{array}$ \\
\hline Familiar Source & $\begin{array}{r}0.18^{*} \\
(0.05)\end{array}$ & $\begin{array}{c}0.01 \\
(0.05)\end{array}$ & $\begin{array}{c}0.13^{*} \\
(0.03)\end{array}$ & $\begin{array}{c}0.10 \\
(0.06)\end{array}$ & $\begin{array}{r}0.09^{*} \\
(0.05)\end{array}$ \\
\hline Affective Polarization & & $\begin{array}{c}0.01^{*} \\
(0.00)\end{array}$ & & & \\
\hline Trump-Biden Therm & & & $\begin{array}{r}-0.01^{*} \\
(0.00)\end{array}$ & & \\
\hline Tax Views & & & & $\begin{array}{c}0.08^{*} \\
(0.01)\end{array}$ & \\
\hline Cyber Concern & & & & & $\begin{array}{c}0.99^{*} \\
(0.03)\end{array}$ \\
\hline$N$ & 2150 & 2150 & 2150 & 1751 & 1751 \\
\hline
\end{tabular}

\section{C.3 Self-Reported Familiarity as a Moderating Variable}

In the analysis in Figure 1, familiar and unfamiliar sources are distinguished based on grouplevel familiarity with these outlets. Here we present a supplementary analysis pooling the control group and unfamiliar source treatment groups of the various studies to use a respondent's perceived familiarity with the unfamiliar source they encountered as a moderating variable (coded as 1 if a respondent said they were aware of the unfamiliar source in that study and 0 otherwise). The table with these results is below. 
Table C5: Perceived Familiarity as Moderator of Unfamiliar Source Effects

\begin{tabular}{lr}
\hline & Pooled \\
\hline Intercept & $-0.06^{*}$ \\
& $(0.02)$ \\
Unfamiliar Source & $0.11^{*}$ \\
& $(0.02)$ \\
Perceived Familiarity & $-0.14^{*}$ \\
& $(0.03)$ \\
Unfamiliar Source $\times$ Perceived Familiarity & -0.01 \\
& $(0.04)$ \\
\hline$N$ & 18954 \\
\hline Standard errors in parentheses & \\
Models include study fixed effects & \\
${ }^{*}$ indicates significance at $p<0.05$ &
\end{tabular}

Here the interaction between perceived familiarity with the unknown source and the effect of the unfamiliar source treatment on opinion is substantively small (-0.01) and not statistically significant. This indicates that perceived familiarity with the unfamiliar source did not increase the effect of encountering its coverage.

We see this pattern as consistent with our findings from the main text. Whether separating unfamiliar and familiar news sources based on their baseline levels of familiarity among the public as a whole (as in Table 1 of the main text) or using individual-level variation in selfreported source familiarity (as in this supplementary analysis), there are limited differences in the effects of different news sources, conditional on exposure.

\section{C.4 Conditional Effects Among Entertainment Seekers}

In additional to the political source only choice tasks, we also included two entertainmentstyle news choice tasks in the second survey. In the entertainment choice tasks respondents had two entertainment options available (randomly assigned from five popular entertainment sources: ESPN (sports), People (lifestyle/celebrity), Food Network (food), Healthline (health) or IGN (entertainment/video games)) in addition to the political news sources. 
Using these tasks, we characterize the effects of unknown news sources among entertainment seekers (those who selected one of the entertainment options) and political news seekers (those who selected one of the political options).

Both groups This shows the effect of unknown sources is slightly larger among those with a preference for entertainment news (a .13 SD effect) relative to those interested in politics (a $.10 \mathrm{SD}$ effect), though we note the difference in the effects between these two groups does not reach statistical significance.

Table C6: Effect of Article from Unfamiliar News Source by News Preference Entertainment Politics

\begin{tabular}{rlr|lr}
\hline & Article Effect & Share & Article Effect & Share \\
\hline Tax Policy (2) & $0.14[0.03,0.25]$ & 0.36 & $0.19[0.11,0.27]$ & 0.64 \\
Cyber Security & $0.12[-0.01,0.24]$ & 0.22 & $0.06[0.01,0.11]$ & 0.78 \\
\hline Pooled & $0.13[0.05,0.21]$ & 0.29 & $0.10[0.05,0.15]$ & 0.71 \\
\hline
\end{tabular}




\section{Appendix D: Supplemental News Choice/News Trust}

\section{Analyses}

\section{D.1 Source Selection By Choice Task}

We break out each news source available in the choice menu for each study and display the probability it was selected by respondents as well as the awareness of the source. In the local news tasks in Study 1, Study 3 and Study 4, the local newspaper was the most prominently used source by respondents. In Study 2 and Study 5 there was a relatively even mix of usage of the various news sources, although we note that few selected RT when it was placed in competition with four high-profile national counterparts.

Table D1: Source Selection by Choice Task

\begin{tabular}{lrrr}
\hline Outlet & Study & Pr(Selected) & Share Aware of Source \\
\hline Non-Profit Local Website & 1 & 0.08 & 0.16 \\
Fake Local Website & 1 & 0.17 & 0.35 \\
Partisan Local Website & 1 & 0.30 & 0.22 \\
Local Newspaper & 1 & 0.41 & 0.76 \\
\hline RT & 2 & 0.03 & 0.10 \\
Huffington Post & 2 & 0.08 & 0.63 \\
USA Today & 2 & 0.22 & 0.81 \\
New York Times & 2 & 0.31 & 0.85 \\
Fox News & 2 & 0.34 & 0.90 \\
\hline Non-Profit Local Website & 3 & 0.11 & 0.16 \\
Partisan Local Website & 3 & 0.13 & 0.22 \\
Fake Local Website & 3 & 0.22 & 0.35 \\
Local Newspaper & 3 & 0.51 & 0.76 \\
\hline Non-Profit Local Website & 4 & 0.09 & 0.18 \\
Partisan Local Website & 4 & 0.13 & 0.26 \\
Fake Local Website & 4 & 0.24 & 0.39 \\
Local Newspaper & 4 & 0.51 & 0.73 \\
\hline RT & 5 & 0.03 & 0.12 \\
Huffington Post & 5 & 0.09 & 0.61 \\
USA Today & 5 & 0.24 & 0.84 \\
New York Times & 5 & 0.29 & 0.86 \\
Fox News & 5 & 0.35 & 0.91 \\
\hline & & & \\
\hline
\end{tabular}




\section{D.2 Trust in Unfamiliar News Sources}

We assess the recognition heuristic below by regressing trust in a news source on whether or not respondents are familiar with it. The expectation from previous work is that familiar news outlets should be more trusted than news outlets a respondent is not familiar with.

Table D2: News Source Trust by Familiarity

\begin{tabular}{lcc}
\hline & Bivariate & W/ Person and Source FEs \\
\hline Familiar with Source & $\begin{array}{c}0.07^{*} \\
(0.002)\end{array}$ & $\begin{array}{c}0.06^{*} \\
(0.002)\end{array}$ \\
\hline Observations & 99,990 & 99,990 \\
\hline Note: & ${ }^{*} \mathrm{p}<0.05$ \\
& Robust Standard Errors, Clustered by Respondent
\end{tabular}

We find evidence of this in our analysis. Familiarity with a news source is associated with greater trust in it, trust in familiar news sources is 7 percentage points higher than trust in unfamiliar news sources across our studies. This pattern persists when incorporating person and source fixed effects into the analysis as we did with news selection in the survey.

We note that while this difference is in the expected direction, it is not particularly large. This may help to explain the relatively similar effects of unfamiliar and familiar news sources on opinion, conditional on exposure to them, though we note the increased trust and news media use that familiar news outlets receive are both consistent with the expectations of the recognition heuristic.

We also consider the sources of trust in the unfamilar news sources used in the experimental treatments of these studies (RT, the partisan local website and the fictional local website). We pool the evaluations of these studies and regress trust in theses sources on a respondent's overall trust in the media (measured with multi-item batteries included in each study and 
re-scaled to have mean zero and standard deviation one) and their partisanship.

Table D3: Predicting Trust in Unfamiliar Sources

\begin{tabular}{|c|c|}
\hline (Intercept) & $\begin{array}{c}0.44^{*} \\
(0.003)\end{array}$ \\
\hline Overall Media Trust & $\begin{array}{c}0.12^{*} \\
(0.002)\end{array}$ \\
\hline Independent & $\begin{array}{l}-0.01^{*} \\
(0.005)\end{array}$ \\
\hline Republican & $\begin{array}{c}0.02^{*} \\
(0.004)\end{array}$ \\
\hline Observations & 33,330 \\
\hline
\end{tabular}

Here partisanship has a small role in evaluations of these sources, with Republicans slightly more trusting of these outlets than Independents or Democrats. A one standard deviation increase in overall media trust has a larger role in trust of these sources, predicting a 12 percentage point increase in trust of the unfamiliar news sources. This suggests those who trust the media in general extend this trust to news sources they are not familiar with.

\section{D.3 Trust and Unfamiliar Source News Use}

To consider the relationship between overall media trust and use of unfamiliar news sources, we combine four separate media trust items included in the survey into a scale using principal components analysis (re-scaled to have mean zero and standard deviation one) and use this to predict whether or not respondents selected the unfamiliar source in the news selection tasks.

This shows there is a relationship between these variables that persists when including partisanship as a control, but that the overall magnitude is relative weak. This is to say, a one 
standard deviation increase in media trust was predicted to make individuals 1 percentage point less likely to select the unfamiliar source in the study. The relationship persists after we condition on political partisanship, showing it is not due to differences in media trust across the political parties. This is relevant, and aligns with the expectation we placed in our pre-analysis plan, but also suggests the need for considering other factors beyond overall media trust that might explain the use of unfamiliar media.

Table D4: $\operatorname{Pr}($ Select Unfamiliar Source) by Overall Media Trust

\begin{tabular}{lcc}
\hline & Bivariate & W/Party \\
\hline (Intercept) & $0.15^{*}$ & $0.14^{*}$ \\
& $(0.00)$ & $(0.00)$ \\
Media Trust & $-0.01^{*}$ & $-0.01^{*}$ \\
& $(0.00)$ & $(0.00)$ \\
Independent & 0.01 \\
& & $(0.01)$ \\
Republican & $0.02^{*}$ \\
& & $(0.01)$ \\
\hline$N$ & 28262 & 28262 \\
\hline Robust standard errors, clustered by Respondent, in parentheses \\
$*$ indicates significance at $p<0.05$
\end{tabular}

